\title{
Impacts of Summer North Atlantic Sea Surface Temperature Anomalies on the East Asian Winter Monsoon Variability
}

\author{
ZHANG CHEN \\ Plateau Atmosphere and Environment Key Laboratory of Sichuan Province, School of Atmospheric Sciences, \\ Chengdu University of Information Technology, Chengdu, China \\ RENGUANG WU \\ School of Earth Sciences, Zhejiang University, Hangzhou, and Center for Monsoon System Research, \\ Institute of Atmospheric Physics, Chinese Academy of Sciences, Beijing, China \\ ZHIBIAO WANG \\ Center for Monsoon System Research, Institute of Atmospheric Physics, Chinese Academy of Sciences, Beijing, China
}

(Manuscript received 23 January 2019, in final form 27 June 2019)

\begin{abstract}
The present study investigates the impacts of the North Atlantic sea surface temperature (SST) anomalies on the East Asian winter monsoon (EAWM) variability. It is found that the northern component of the EAWM variability is associated with a dipole pattern of preceding summer North Atlantic SST anomalies during 1979-2016. The processes linking preceding summer North Atlantic SST to EAWM include the North Atlantic air-sea interactions and atmospheric wave train triggered by the North Atlantic SST anomalies. Atmospheric wind anomalies in the preceding spring-summer result in the formation of a dipole SST anomaly pattern through surface heat flux changes. In turn, the induced SST anomalies provide a feedback on the atmosphere, modifying the location and intensity of anomalous winds over the North Atlantic. The associated surface heat flux anomalies switch the North Atlantic SST anomaly distribution from a dipole pattern in summer to a tripole pattern in the following winter. The North Atlantic tripole SST anomalies excite an atmospheric wave train extending from the North Atlantic through Eurasia to East Asia in winter, resulting in anomalous EAWM. However, the relationship of the northern component of EAWM to preceding summer North Atlantic SST anomalies is weak before the late 1970s. During 1956-76, due to weak air-sea interaction over the North Atlantic, no obvious tripole SST anomaly pattern is established in winter. The atmospheric wave train in winter is located at higher latitudes, leading to a weak connection between the northern component of EAWM and the preceding summer North Atlantic dipole SST anomaly pattern.
\end{abstract}

\section{Introduction}

The East Asian winter monsoon (EAWM) is one of the most active components in the global climate system during boreal winter, and it exerts large impacts on the Asia-Pacific winter climate. The most prominent surface feature of the EAWM is that northerly winds extend from the midlatitude East Asia to the equatorial South China Sea (Chen et al. 2000; Wang et al. 2010). Recent studies demonstrated that the EAWM variability is dominated by two distinct components: the northern (midlatitude) and southern (low latitude)

Corresponding author: Renguang Wu, renguang@zju.edu.cn components (e.g., Wu et al. 2006; Kang et al. 2009; Wang et al. 2010; Liu et al. 2012; Chen et al. 2014a). The two components have notably different circulation systems and factors. The midlatitude component of the EAWM variability is linked to the mid- and high-latitude circulation systems (Liu et al. 2012, 2013; Chen et al. 2014a) and has a close relationship with autumn Arctic sea ice concentration changes (Chen et al. 2014b), whereas the low-latitude component of the EAWM variability is related to circulation systems over global tropics and is influenced by El Niño-Southern Oscillation (ENSO) (Liu et al. 2012, 2013; Chen et al. 2014a). Therefore, the two components of the EAWM variability should be investigated separately and two indices are needed to 
measure the strength of these two components respectively (e.g., Liu et al. 2012; Chen et al. 2014a).

Sea surface temperature (SST) plays an important role in climate variability. A number of studies have demonstrated the impacts of the North Atlantic SST anomalies on atmospheric circulation over Eurasia (e.g., Li 2004; Wu et al. 2009; Wu et al. 2010, 2011; Liu et al. 2014; Chen et al. 2016). Wu et al. (2009) found that an anomalous North Atlantic Oscillation (NAO) in spring may induce a tripole SST anomaly pattern in the North Atlantic Ocean that persists into ensuing summer and excites downstream development of subpolar teleconnection across the northern Eurasia, leading to anomalous East Asian summer monsoon. Wu et al. (2010, 2011) revealed a close relationship between northeast China summer temperature and a tripole SST anomaly pattern in the North Atlantic Ocean during the preceding spring. Chen et al. (2016) indicated the role of the North Atlantic tripole SST anomaly pattern in the formation of tripole surface air temperature (SAT) anomalies over mid- and high-latitude Eurasia in spring. Li (2004) and Liu et al. (2014) showed the role of the North Atlantic SST anomalies in the formation of the Eurasian (EU) pattern.

Several studies suggest that the linkages between the North Atlantic SST and several climate components are unstable (e.g., Wu et al. 2011; Wu and Zhang 2015; Chen et al. 2015; Chen and Wu 2017; Wang et al. 2019). Marked interdecadal changes were detected in the connection of spring North Atlantic tripole SST anomaly pattern with spring Eurasian SAT anomalies (Chen and $\mathrm{Wu}$ 2017) and summer northeastern China temperature anomalies (Wu et al. 2011). Nonstationary relationships were also observed between the interannual variations of boreal winter NAO and northern tropical Atlantic SST (Chen et al. 2015), between the North Atlantic SST and EU pattern (Wang et al. 2019), and between the spring NAO and summer Pamir-Tienshan snow cover (Wu and $\mathrm{Wu} 2019$ ).

Previous studies regarding the connection between the Eurasian climate variability and the North Atlantic SST primarily focused on spring and summer Eurasian climate or winter North Atlantic SST influence. Few studies have examined the influence of the North Atlantic SST in the preceding seasons on winter circulation over Eurasia. This study aims to investigate the role of preceding summer North Atlantic SST anomalies in the EAWM variability on the interannual time scale and inspect whether the relationship between them has been subjected to interdecadal changes in the past. Furthermore, the present study considers the two components of EAWM variability separately. The rest of the paper is organized as follows. Section 2 describes datasets and methods. Section 3 presents the relationship between the EAWM and the North Atlantic SST. Section 4 investigates the possible physical processes connecting summer North Atlantic SST to EAWM. Section 5 explores the observational evidence for the interdecadal changes in the North Atlantic SST-EAWM relationship. Section 6 gives a summary along with discussions.

\section{Data and methodology}

The present study uses monthly mean SSTs from the Met Office Hadley Centre Sea Ice and Sea Surface Temperature (HadISST) dataset on a $1.0^{\circ} \times 1.0^{\circ}$ grid (Rayner et al. 2003). The National Centers for Environmental Prediction-National Center for Atmospheric Research (NCEP-NCAR) reanalysis (Kalnay et al. 1996) provides monthly mean geopotential height at 500 and $200 \mathrm{hPa}$; winds at 1000,850 , and $500 \mathrm{hPa}$; surface winds; surface air temperature; sea level pressure (SLP); and surface heat fluxes (including latent and sensible heat flux and shortwave and longwave radiation) for the present study. Surface winds, surface air temperature, SLP, and surface heat fluxes are on T62 Gaussian grids. Geopotential height and winds at pressure levels are on a regular $2.5^{\circ}$ latitude-longitude grid. The convention for surface heat fluxes is positive for downward flux. The European Centre for Medium-Range Weather Forecasts interim reanalysis (ERA-Interim) (Dee et al. 2011), the Japanese 55-yr Reanalysis (Kobayashi et al. 2015), and the SST from the National Oceanic and Atmospheric Administration (NOAA) (Smith et al. 2008) were also used for the purpose of verification. The obtained results are very similar and thus we only present figures based on HadISST and NCEP-NCAR reanalysis.

Following Chen et al. (2014a), we used DecemberFebruary (DJF) area-mean 1000-hPa meridional wind anomalies over the regions $10^{\circ}-25^{\circ} \mathrm{N}, 105^{\circ}-135^{\circ} \mathrm{E}$ and $35^{\circ}-55^{\circ} \mathrm{N}, 110^{\circ}-125^{\circ} \mathrm{E}$ to represent the southern and northern components of the EAWM variability, respectively, which are denoted as the Sindex and Nindex. Note that these two indices have been multiplied by -1 so that a high index corresponds to a strong EAWM. The 2016 winter refers to the three months from December 2016 to February 2017. We focus on interannual time scale variations that are extracted by applying a 9-yr high-pass Lanczos filter (Duchon 1979) to original monthly mean anomalies.

ENSO contributes to the North Atlantic SST change (e.g., Klein et al. 1999) as well as the EAWM variability (e.g., Wang et al. 2010; Chen et al. 2014a). This raises the possibility that the relationship between the North Atlantic SST anomaly and the EAWM variability is due to the influence of ENSO on both of them. To exclude the 
possible influence of ENSO, we derived the component of all the variables independent of ENSO by removing the ENSO-related variation through a linear regression with respect to the winter Niño-3.4 SST index. The Niño-3.4 SST anomalies averaged over the region of $5^{\circ} \mathrm{S}-5^{\circ} \mathrm{N}$ and $170^{\circ}-120^{\circ} \mathrm{W}$ are used as an index for ENSO. The EAWM variability and SST anomalies independent of ENSO are termed as Nindex(nonENSO), Sindex (nonENSO), and SST(nonENSO), respectively.

\section{The relationship between the North Atlantic SST and the EAWM variability}

To explore the relationship between the North Atlantic SST and the two components of the EAWM variability, we perform a correlation analysis of the North Atlantic SST anomalies in preceding months with respect to $\mathrm{D}(0) \mathrm{JF}(1)$ Nindex and Sindex separately (Figs. 1, 2). The figures are displayed as consecutive twomonth means, including May-June(0), July-August(0), September-October(0), November-December(0), and January-February(1). The numerals " 0 " and " 1 " denote the current year and the next year, respectively.

The distribution of correlation corresponding to the Nindex is characterized by a dipole pattern in the preceding May-June(0) with significant negative and positive correlation in the midlatitude and subtropical North Atlantic, respectively (Fig. 1a). This dipole distribution is maintained in the subsequent July-August $(0)$ and September-October $(0)$ and attains the maximum in July-August(0) (Figs. 1b,c). Both negative and positive correlation regions move southward in NovemberDecember(0) with two centers located in the subtropics and tropics, respectively (Fig. 1d). The correlation coefficient becomes small in January-February(1) in most regions except off the coast of the Newfoundland (Fig. 1e).

Corresponding to the Sindex, the correlation coefficient is weak in May-June(0) (Fig. 2a), NovemberDecember(0) (Fig. 2d), and January-February(1) (Fig. 2e). In July-August(0) and September-October(0), significant negative and positive correlations are located in limited regions of the midlatitude and subtropical North Atlantic, respectively (Figs. 2b,c). This pattern appears somewhat similar to that corresponding to the Nindex. Nevertheless, the significant correlation regions are much smaller and the correlation coefficients have smaller magnitude for the Sindex than for the Nindex (Figs. 2b,c vs Figs. 1b,c). Thus, we only investigate the effects of the North Atlantic SST anomalies on the northern component of EAWM variability in this study.

According to Fig. 1b, a North Atlantic dipole SST index (SSTI) is defined as the difference in area-mean July-August SST anomalies between regions of positive and negative correlation (see the boxes in Fig. 1b). A positive SSTI denotes positive SST anomalies in the subtropics and negative SST anomalies in the midlatitudes. July-August is chosen for defining the SSTI as it is the time when the dipole pattern in the SST correlation distribution is most pronounced. The time series of July-August SSTI and its component unrelated to ENSO, which is denoted as SSTI(nonENSO), are shown in Fig. 3. The correlation coefficient between the SSTI and the following winter Niño-3.4 SST is 0.42 for the period 1979-2016. The percent variance explained by the ENSO-independent component of the SSTI is about $82.6 \%$. The correlation coefficient of SSTI and SSTI (nonENSO) with the following winter Nindex is 0.53 and 0.73 , respectively, both exceeding the $95 \%$ confidence level according to the Student's $t$ test. This result confirms that there is a close relationship between the preceding summer North Atlantic dipole SST anomaly pattern and the northern component of the EAWM variability on the interannual time scale.

\section{Physical processes connecting summer North Atlantic SST to EAWM}

What are the plausible physical processes that link the summer North Atlantic dipole SST anomaly pattern to the northern component of the EAWM variability? To address this question, first we analyze the spatiotemporal evolution of the North Atlantic SST anomalies from summer to winter, and then we investigate the winter atmospheric circulation anomalies related to the North Atlantic SST anomaly pattern. The descriptions in the following correspond to positive SSTI years, but also apply to negative SSTI years except for a switch in the sign of anomalies.

\section{a. Evolution of the North Atlantic SST anomalies}

A dipole SST anomaly pattern appears in MarchApril in the North Atlantic with significant negative and positive anomalies in the midlatitudes and subtropics, respectively (Fig. 4a). The dipole SST pattern intensifies in May-June (Fig. 4b), attains the maximum strength in July-August (Fig. 4c), and persists to SeptemberOctober (Fig. 4d). In November-December, the dipole SST anomalies shift southward and negative and positive SST anomalies are located in the subtropics and tropics, respectively. Positive SST anomalies form in the midlatitudes (Fig. 4e). Thus, the distribution of the SST anomalies in the North Atlantic forms a tripole pattern in November-December (Fig. 4e). This tripole SST anomaly pattern is maintained to January-February (Fig. 4f) with the extents of significant SST anomalies becoming smaller in the subtropical and tropical regions 


\section{SST cor. Nindex (nonENSO) in 1979-2016}

(a) May-June(0)

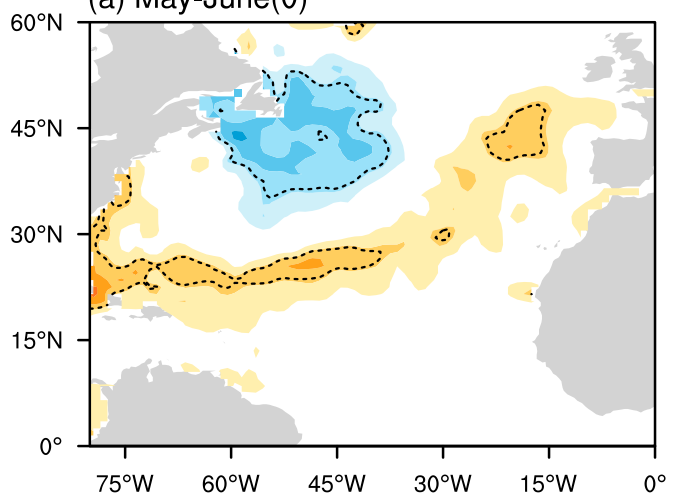

(c) Sep.-Oct.(0)

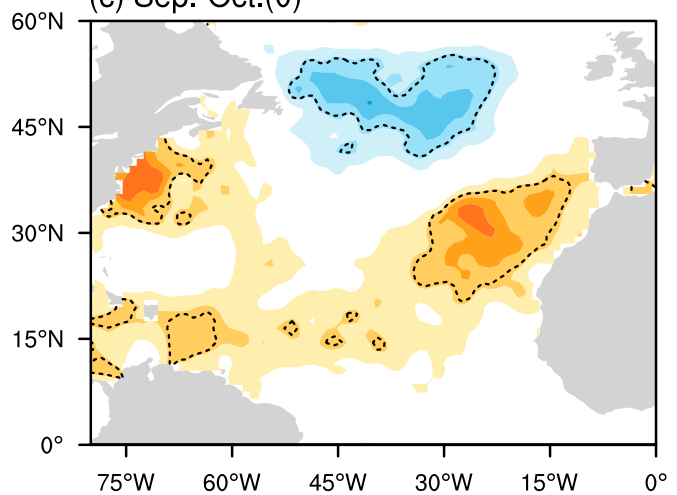

(b) July-Aug(0)

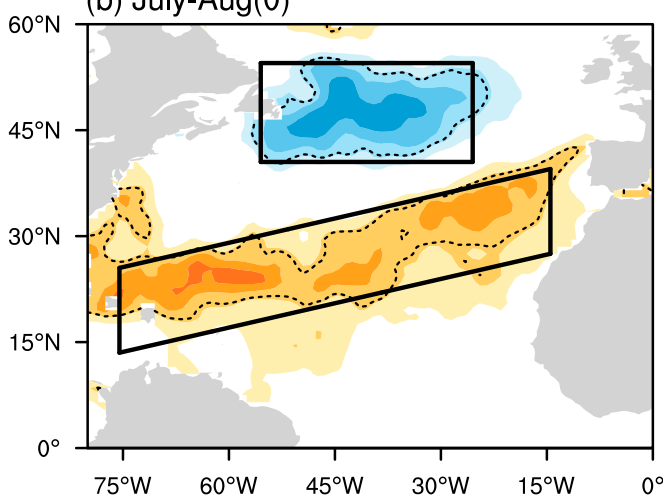

(d) Nov.-Dec.(0)

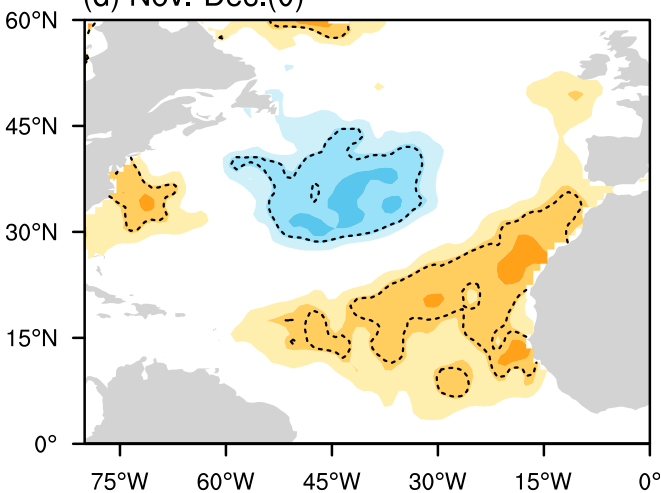

(e) Jan.-Feb.(1)

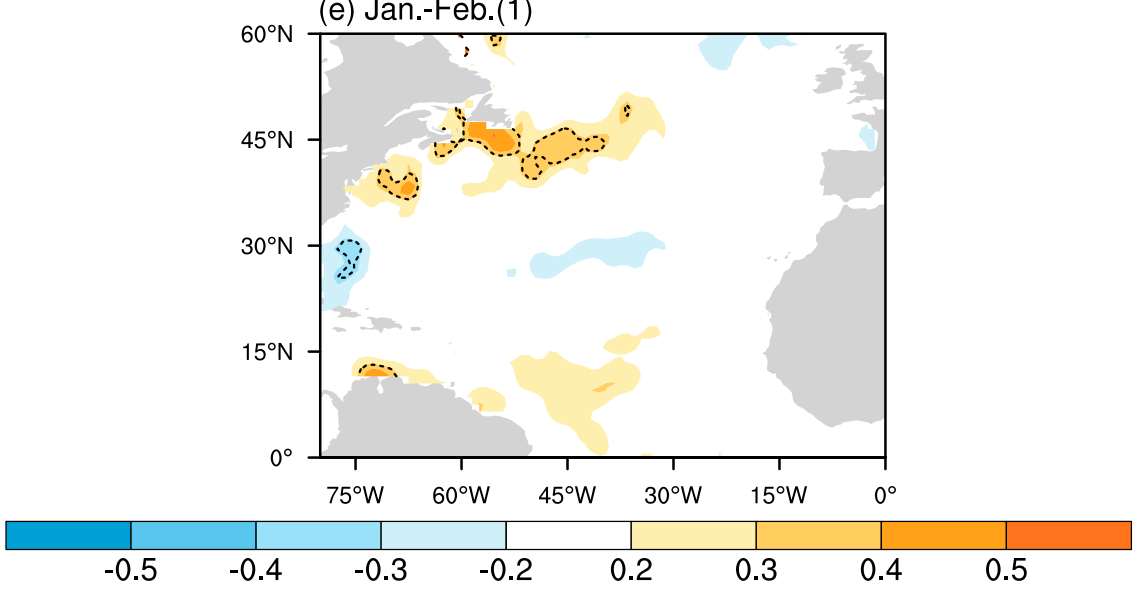

FIG. 1. Correlation coefficients between the Nindex of EAWM and SST anomalies in the preceding (a) MayJune(0), (b) July-August(0), (c) September-October(0), (d) November-December(0), and (e) simultaneous January-February(1) based on the period 1979-2016. The ENSO signal has been removed. The dashed contours denote that the correlation coefficients are significant at the $95 \%$ confident level according to the Student's $t$ test. The two domains enclosed by thick lines in (b) denote the regions that are used to define the North Atlantic dipole SSTI.

and larger in the midlatitude region than those in November-December (Fig. 4f vs Fig. 4e).

Previous studies suggested that the development of the North Atlantic SST anomalies may be due to changes in atmospheric circulation (e.g., Hu and Huang 2006; Wu et al. 2011). To confirm the role of atmospheric circulation in the North Atlantic SST change, we examine the evolution of surface wind anomalies (Fig. 4) and surface heat 


\section{SST cor. Sindex (nonENSO) in 1979-2016}
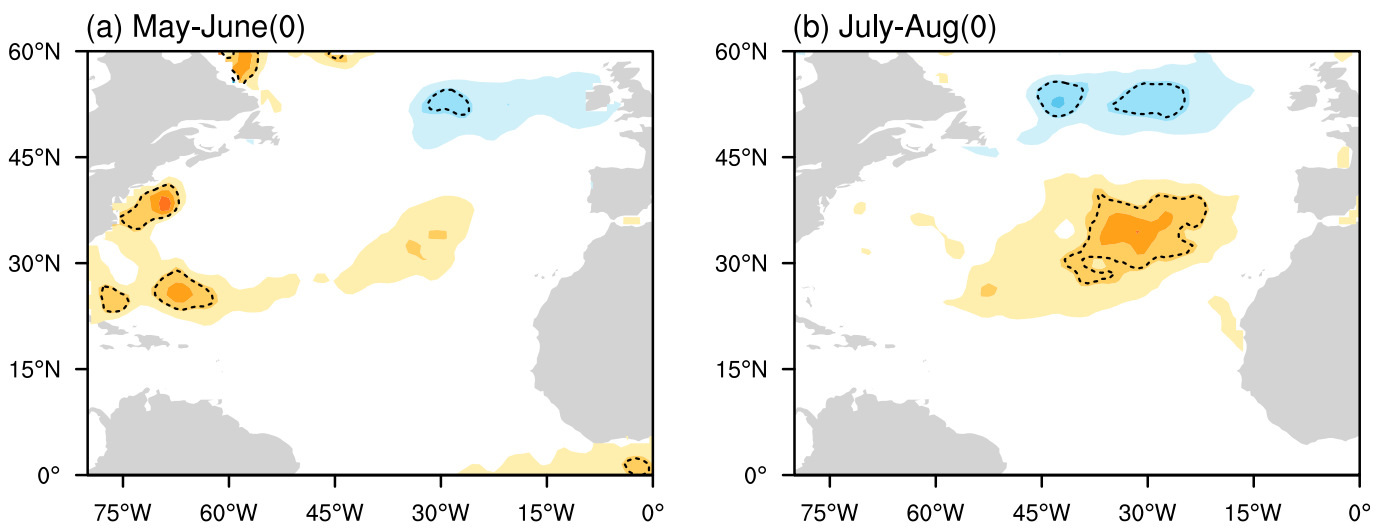

(c) Sep.-Oct.(0)

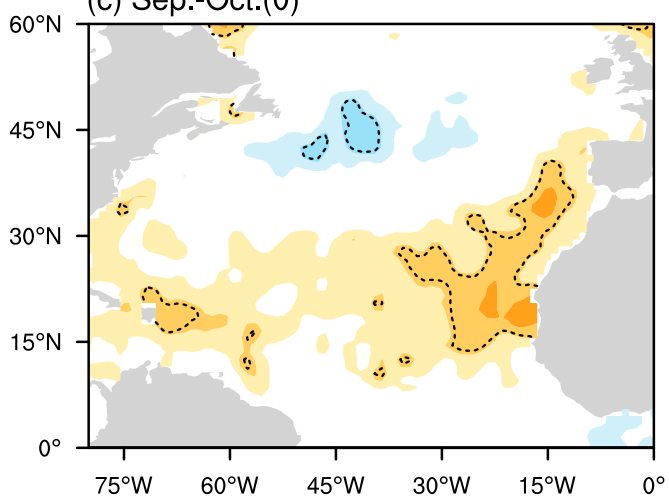

(d) Nov.-Dec.(0)
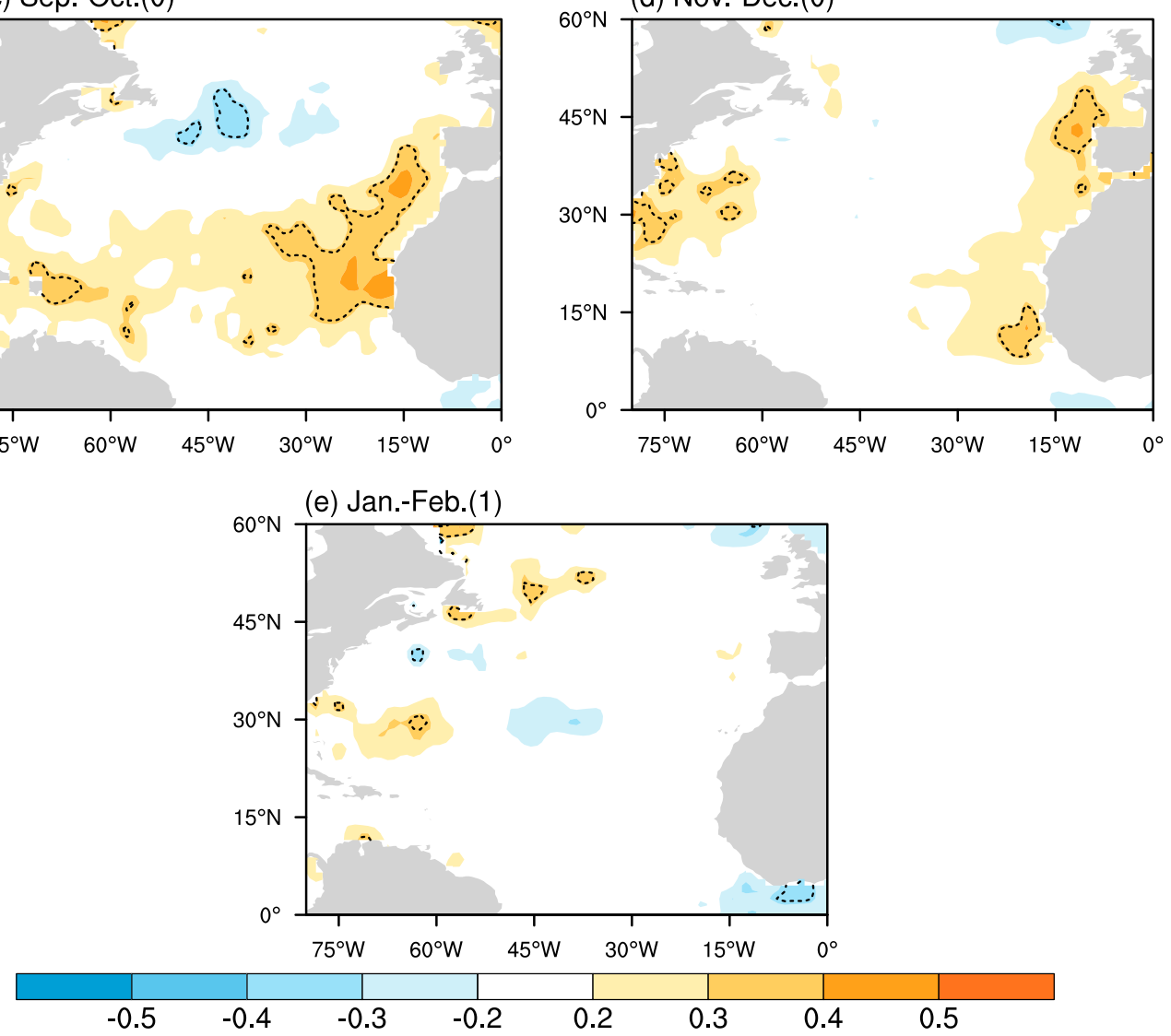

FIG. 2. As in Fig. 1, but for the correlation coefficients between the Sindex of EAWM and SST anomalies.

flux anomalies (Fig. 5) over the North Atlantic obtained by regression against the July-August SSTI during 19792016. Since sensible heat flux (SHF) anomalies are much smaller than latent heat flux (LHF) anomalies (with same sign) and longwave radiation (LWR) anomalies are smaller than shortwave radiation (SWR) anomalies (with opposite sign), we only show LHF and SWR anomalies. For the LHF anomalies, we estimated the relative contributions of surface wind speed and sea-air humidity difference based on a linearization of LHF formula following Tanimoto et al. (2003) (figures not shown).

In March-April, an anomalous cyclone occupies the central basin and an anomalous anticyclone lies over the eastern basin (Fig. 4a). The westerly wind anomalies over the midlatitude western North Atlantic (Fig. 4a) bring drier air from the land, increasing the sea-air 


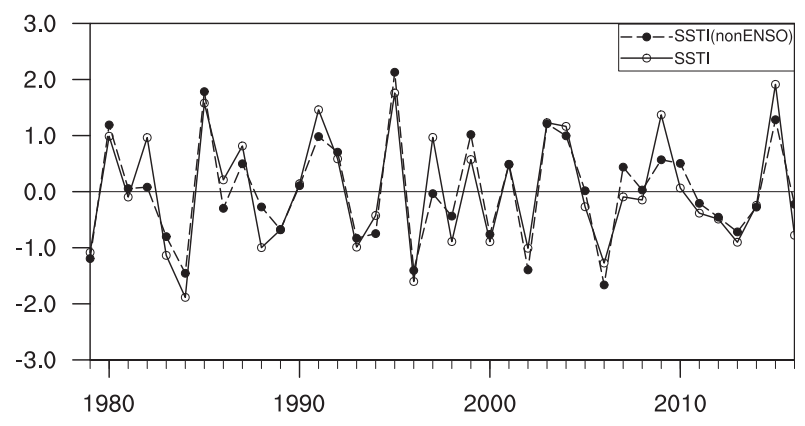

FIG. 3. The normalized interannual time series of the July-August North Atlantic dipole SSTI (solid curve) and SSTI (nonENSO) (dashed curve) for the period 1979-2016.

humidity difference and enhancing LHF from ocean to atmosphere (Fig. 5a), which contributes to negative SST anomalies there (Fig. 4a). The positive LHF anomalies over the midlatitude eastern North Atlantic (Fig. 5a) are associated with anomalous southerly winds (Fig. 4a) that bring wetter air from lower latitudes, reducing the seaair humidity difference. Over the subtropics, anomalous southwesterly winds reduce wind speed and suppress upward LHF over the central basin (Fig. 5a) and anomalous anticyclonic winds reduce cloudiness (figure not shown) and enhance downward SWR over the eastern basin (Fig. 5b). Together, they contribute to the SST increase in the subtropics (Fig. 4a).

In May-June, an anomalous cyclone dominates the midlatitudes (Fig. 4b). Cold SST anomalies are present in the northwestern part of the cyclone under anomalous northerly winds, and warm SST anomalies cover the eastern and southern part of the cyclone under anomalous southerly and westerly winds, respectively (Fig. 4b). The spatial phase relation between wind and SST anomalies suggests that air-sea interaction processes may be at work (Hu and Huang 2006). On one hand, the anomalous cyclone appears to be a Rossby wave response to warm SST anomalies. On the other hand, the southwesterly wind anomalies over the subtropical North Atlantic weaken the northeasterly trade winds and reduce upward LHF (Fig. 5c), enhancing positive SST anomalies (Fig. 4b). The northerly wind anomalies over the western North Atlantic bring dryer air from higher latitudes and increase the sea-air humidity difference and thus increase upward LHF (Fig. 5c). Negative SST anomalies near the center of the anomalous cyclone (Fig. 4b) are also contributed by negative SWR anomalies (Fig. 5d) in association with cyclone-related cloudiness increase (figure not shown). The air-sea coupled processes lead to increase in SST and wind anomalies from May-June to July-August (Figs. 4b,c).

In July-August, the anomalous cyclone moves eastward in the midlatitudes (Fig. 4c). This feature may be due to the feedback of SST anomalies. The low-level convergence may be enhanced over the positive SST anomaly regions and weakened over the negative SST anomaly regions (Lindzen and Nigam 1987), which is favorable to the eastward move of the anomalous cyclone. In turn, the northerly wind anomalies increase the sea-air humidity difference and the westerly wind anomalies strengthen local wind speed, both leading to an increase in upward LHF over central-eastern midlatitudes (Fig. 5e). In addition, SWR is suppressed (Fig. 5f) in the region of anomalous cyclone (Fig. 4c). Together, these lead to the eastward extension of negative SST anomalies in the midlatitudes (Fig. 4c). The anomalous westerly winds around $15^{\circ} \mathrm{N}$ reduce surface wind speed, contributing to positive LHF anomalies (Fig. 5e). Under the influence of negative SST anomalies, the anomalous cyclone is weakened over the midlatitudes and moves southward to the subtropics in the following September-October (Fig. 4d).

In September-October, an anomalous anticyclone develops over the midlatitude North Atlantic (Fig. 4d). The LHF anomaly pattern is characterized by a tripole pattern (Fig. 5g). Positive LHF anomalies are observed over the midlatitudes and tropics and negative LHF anomalies are located over the subtropics. The LHF anomalies over the tropics and subtropics may be due to the wind speed effect as anomalous winds are opposite to and in the same direction as climatological mean winds in the tropics and subtropics, respectively (Fig. 4d). The positive LHF anomalies over the midlatitudes (Fig. 5g) may be due to the effects of sea-air humidity difference as anomalous southerly winds along the west coast of the North Atlantic (Fig. 4d) bring wetter air from lower latitudes and reduce the sea-air humidity difference. SWR anomalies appear small in most of the North Atlantic basin (Fig. 5h). The LHF anomalies have a negative contribution to the dipole SST anomalies, leading to the decrease of both positive SST anomalies in the subtropics and negative SST anomalies in the midlatitudes (Fig. 4d).

The anomalous cyclone over the North Atlantic is intensified in November-December (Fig. 4e). The spatial distribution of LHF anomalies in NovemberDecember features a tripole pattern (Fig. 5i) as in September-October (Fig. 5g) but with negative anomalies shifting westward over the subtropics. SWR anomalies are small (Fig. 5j). Positive LHF anomalies in the midlatitudes and tropics are related to the wind speed decrease as anomalous winds are against climatological mean winds (Fig. 4e). Negative LHF anomalies over the western subtropics appear to be due to the increase of sea-air humidity difference under the influence of anomalous northerly winds (Fig. 4e). Positive 
(a) Mar.-Apr.(0)

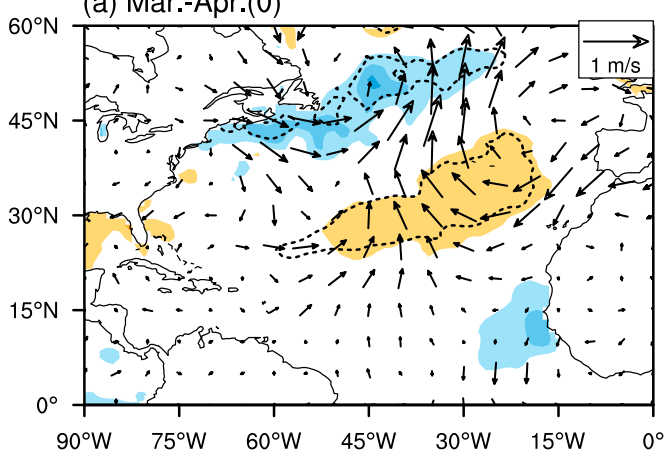

(c) July-Aug(0)

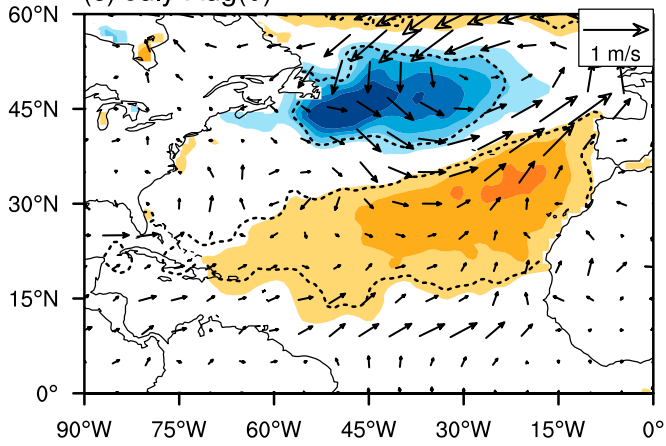

(e) Nov.-Dec.(0)

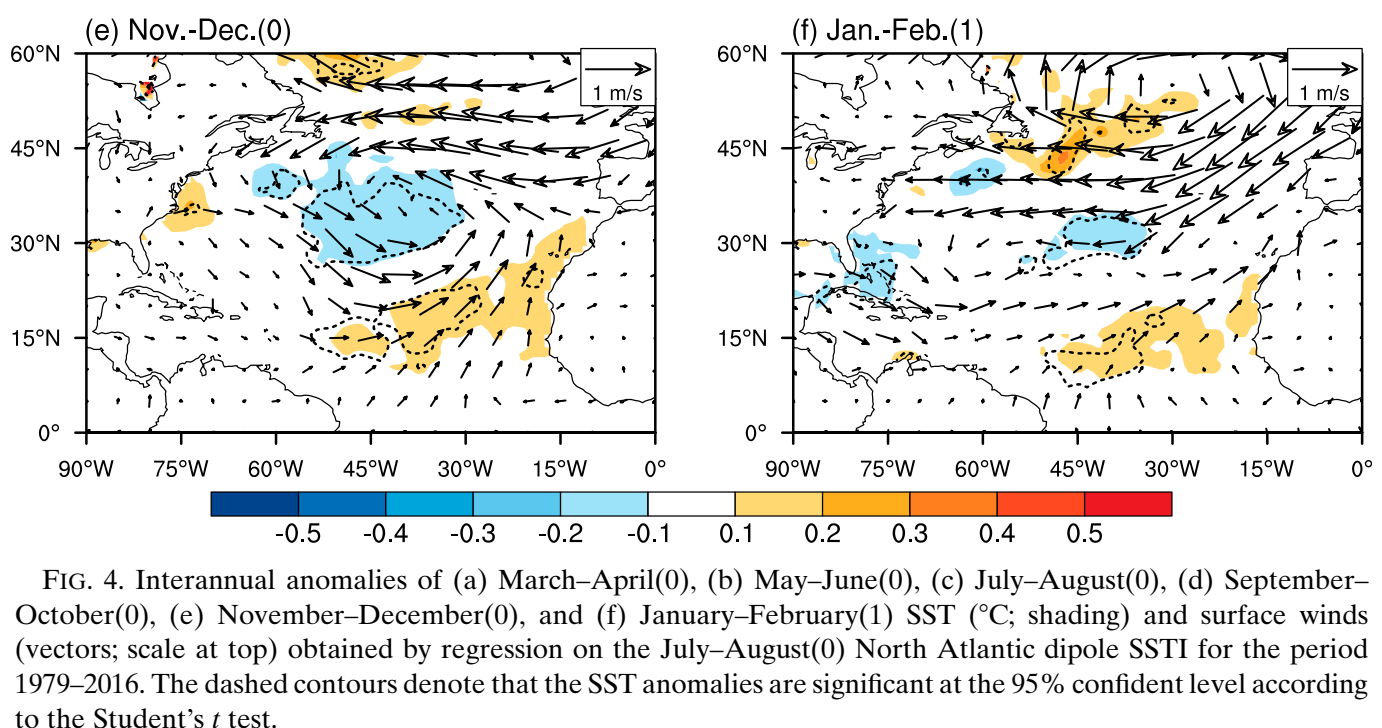

FIG. 4. Interannual anomalies of (a) March-April(0), (b) May-June(0), (c) July-August(0), (d) SeptemberOctober(0), (e) November-December(0), and (f) January-February(1) SST $\left({ }^{\circ} \mathrm{C}\right.$; shading) and surface winds (vectors; scale at top) obtained by regression on the July-August(0) North Atlantic dipole SSTI for the period 1979-2016. The dashed contours denote that the SST anomalies are significant at the $95 \%$ confident level according to the Student's $t$ test.

LHF anomalies in the midlatitudes contribute to the switch of the SST anomalies from negative to positive (Fig. 4e). Negative LHF anomalies (Fig. 5i) contribute to the negative SST anomalies (Fig. 4e) in the subtropics. The persistence of positive SST anomalies in the tropics (Fig. 4e) may be explained by positive LHF anomalies (Fig. 5i). As a result, the dipole SST anomaly pattern changes to a tripole SST anomaly pattern in November-October (Figs. 4d,e).

In January-February, an anomalous anticyclone covers the midlatitudes and an anomalous cyclone covers the

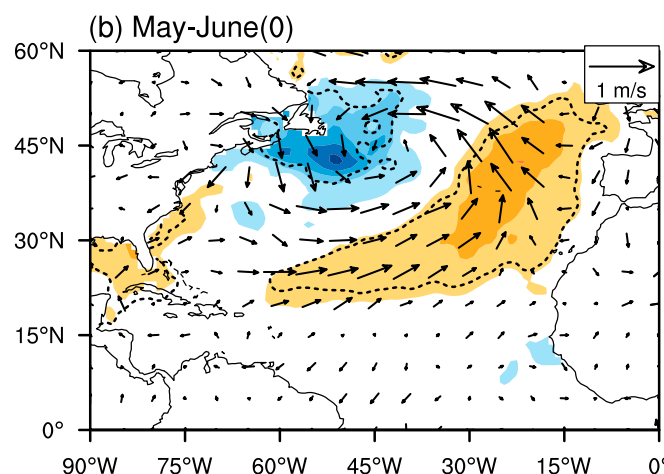

(d) Sep.-Oct. (0)

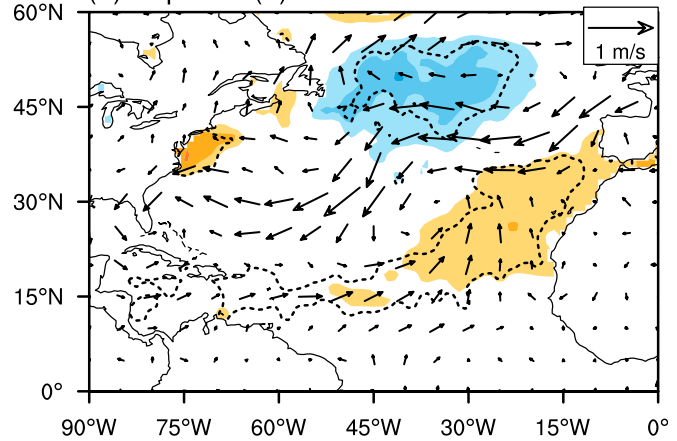

subtropics (Fig. 4f). The anomalous easterly winds over the midlatitudes weaken upward LHF (Fig. 5k), favoring the increase of positive SST anomalies there and weakening and southward retreat of negative SST anomalies in the subtropics (Fig. 4f). The LHF anomalies decrease over the tropics (Fig. 5k) following the weakening of anomalous southwesterly winds (Fig. 4f). The SWR anomalies are small (Fig. 51).

The SST change is contributed by both surface heat fluxes and oceanic processes. A complete heat budget analysis would be needed to understand the respective 

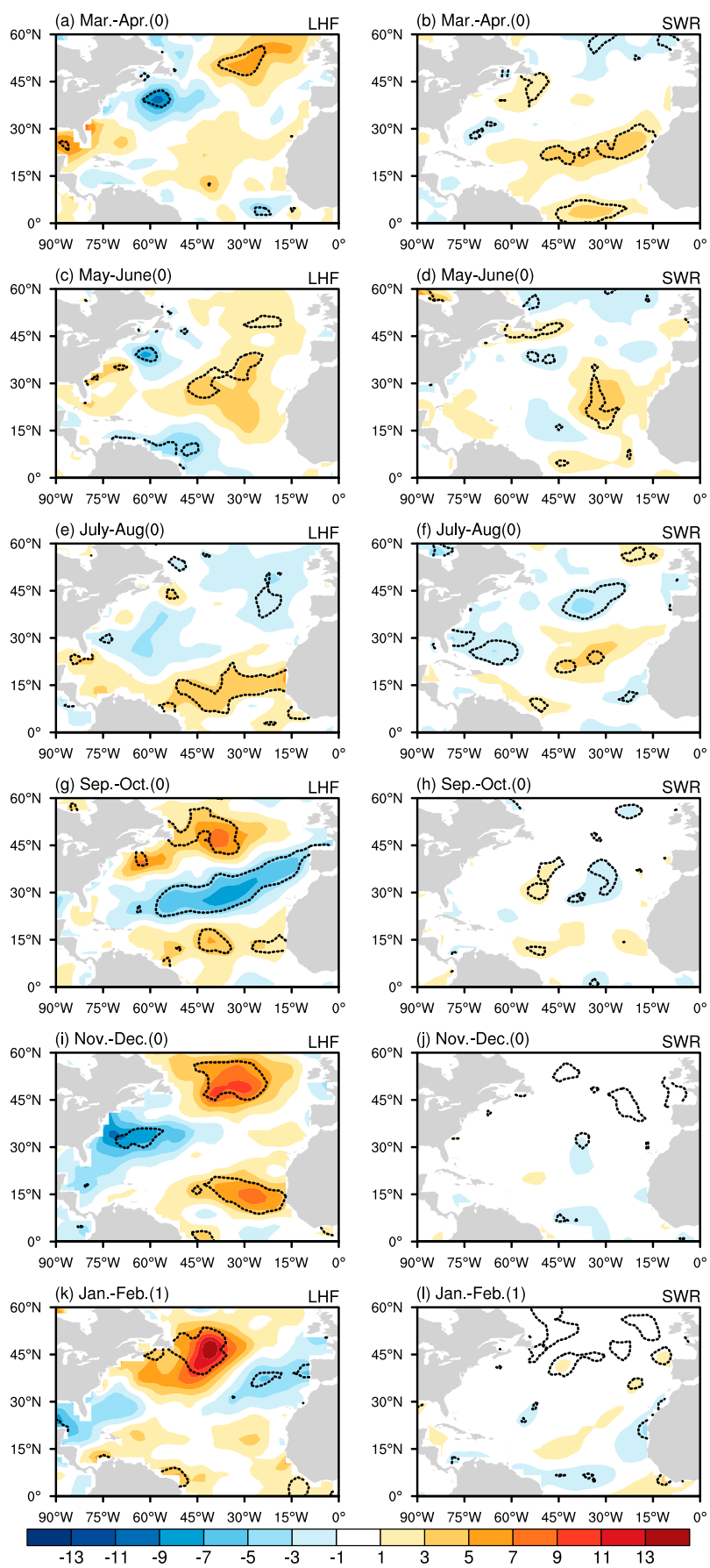

FIG. 5. Interannual anomalies $\left(\mathrm{W} \mathrm{m}^{-2}\right)$ of (a),(b)March-April(0), (c),(d) May-June(0), (e),(f) July-August(0), (g),(h) SeptemberOctober(0), (i),(j) November-December(0), and (k),(l) JanuaryFebruary(1) (left) LHF and (right) SWR obtained by regression on the July-August(0) North Atlantic dipole SSTI for the period 19792016. The dashed contours denote that the anomalies are significant at the $95 \%$ confident level according to the Student's $t$ test. The convention for surface heat fluxes is positive for downward flux. contributions of various terms to the SST change. However, due to biases and inconsistencies in the input data, large unbalance is often encountered in the mixed layer heat budget. Here, we focus on the contribution of surface heat flux to the SST change and so a complete heat budget analysis is not conducted. The contribution of oceanic processes is inferred from the difference between the SST tendency and surface heat fluxes. Figure 6 shows the SST tendency, net surface heat flux (NHF) anomalies, and the residual term that is the difference of the SST tendency minus NHF anomalies. The residual term includes the effects of the oceanic processes and the mixed layer depth change as well as biases in the estimation of surface heat fluxes. The SST tendency at a specific month is calculated as the difference of SST in the succeeding month minus that in the preceding month divided by 2 . For convenience of comparison, the unit of SST tendency has been converted from degrees Celsius per month $\left({ }^{\circ} \mathrm{C}\right.$ month $\left.{ }^{-1}\right)$ to watts per square meter $\left(\mathrm{W} \mathrm{m}^{-2}\right)$ by multiplying it with $\rho_{o} C_{p} h$, where $\rho_{o}, C_{p}$, and $h$ are the water density, specific heat at constant pressure for ocean, and the mixed layer depth, respectively.

In March-April, the negative SST tendency in the western midlatitudes and the positive SST tendency in the subtropics are largely contributed by NHF (Figs. 6a,b). The positive SST tendency in the eastern midlatitudes is contributed by both NHF and the residual term (Figs. 6b,c). The positive residual term may include the Ekman advection effect associated with anomalous northeasterlies (Fig. 4a). In May-June, the positive SST tendency in the subtropics is mainly due to NHF, whereas the negative SST tendency in the midlatitudes is largely due to the residual term (Figs. 6d-f) that may include anomalous upwelling due to anomalous cyclonic winds (Fig. 4b). In July-August, the negative SST tendency in the midlatitudes is mainly due to NHF and the positive SST tendency in the subtropics results from a combination of NHF and the residual term (Figs. 6g-i). In September-October, the SST tendency in tropics and subtropics is mainly due to NHF (Figs. 6j-1). In November-December, the SST tendency displays a tripole pattern, which is similar to NHF anomalies except for the westward shift of the negative region in the subtropics (Figs. 6m,n). In JanuaryFebruary, NHF has a major contribution to the positive SST tendency in the midlatitudes and the negative SST tendency in the western subtropics (Figs. 6p,q). The positive SST tendency appears to have a small contribution from NHF in the tropics. The residual term appears to have a negative effect for the SST change in the midlatitudes in November-December and JanuaryFebruary (Figs. 6o,r). Overall, surface heat fluxes are 

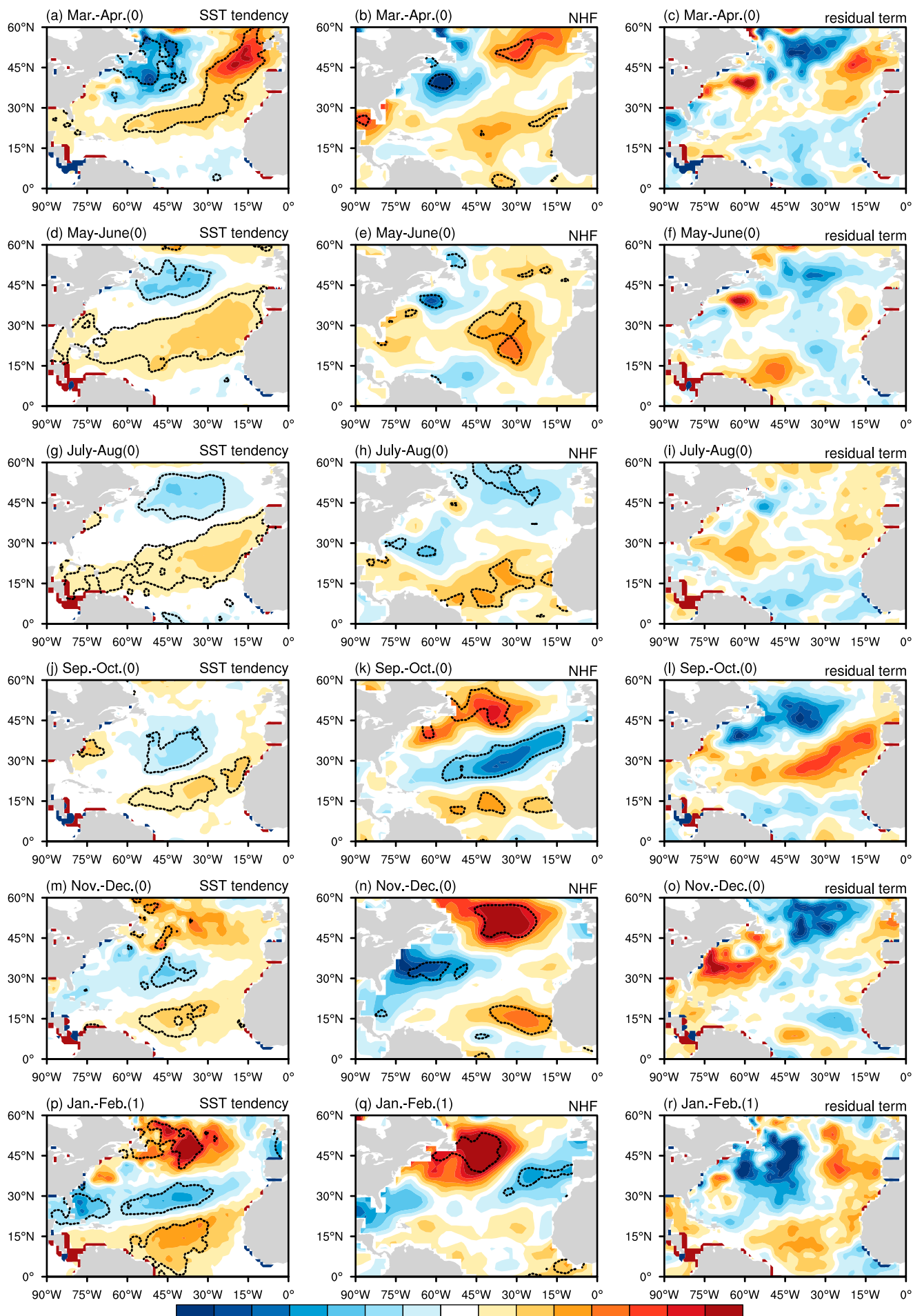

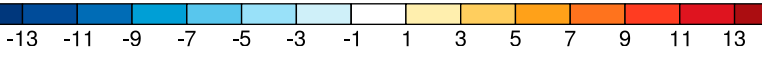

FIG. 6. Interannual anomalies ( $\mathrm{W} \mathrm{m}^{-2}$ ) of (left) SST tendency, (center) NHF, and (right) the residual term in (a)-(c) March-April(0), (d)-(f) May-June(0), (g)-(i) July-August(0), (j)-(l) September-October(0), (m)-(o) November-December(0), and (p)-(r) January-February(1) obtained by regression on the July-August $(0)$ North Atlantic dipole SSTI for the period 1979-2016. The dashed contours denote that the anomalies are significant at the $95 \%$ confident level according to the Student's $t$ test. The convention for surface heat fluxes is positive for downward flux. 
important in the spatial-temporal evolution of the SST anomalies.

As noted above, LHF and SWR are two main terms in NHF anomalies. The relative contributions of LHF and SWR to NHF anomalies vary with the season. In spring and summer (March-April, May-June, and July-August), both LHF and SWR are important to the NHF anomalies (Figs. 5a-f, 6b,e,h). However, the LHF is predominantly responsible for NHF anomalies and the magnitude of SWR anomalies is much smaller than that of LHF anomalies in fall and winter (Figs. 5g-1, $6 \mathrm{k}, \mathrm{n}, \mathrm{q})$.

The above analyses indicate an air-sea feedback mechanism in the evolution of SST and wind anomalies. On one hand, the wind anomalies contribute to the formation and maintenance of SST anomalies through modulating surface wind speed and cloud and then LHF and SWR. On the other hand, the SST anomalies modify the location and intensity of anomalous winds through a Rossby wave type response. Thus, the air-sea interaction is likely responsible for the evolution of the North Atlantic SST anomalies from summer to winter. The evolution of anomalies over the North Atlantic displays both similarity and difference compared to that obtained by Hu and Huang (2006, see their Fig. 3). The wind anomalies during spring and summer are similar to $\mathrm{Hu}$ and Huang (2006), and so are the SST anomalies in the midlatitudes and subtropics. A notable difference is that positive SST anomalies in the high-latitude North Atlantic during summer are obvious in $\mathrm{Hu}$ and Huang (2006), but not seen in the present study. The wind and SST anomalies during fall and winter display a large discrepancy. One difference is that the anomalous cyclone moves northeastward to the midlatitudes in fall and winter in $\mathrm{Hu}$ and Huang (2006), but shifts southward to the subtropics in our study. Another difference is that the SST anomalies in the midlatitude become weak in winter in $\mathrm{Hu}$ and Huang (2006), but change to a tripole pattern in winter in the present study. The above discrepancy is likely due to the difference of focus. $\mathrm{Hu}$ and Huang (2006) focused on the physical process associated with the North Atlantic horseshoe-like SST anomaly pattern in summer, whereas the present study focuses on the SST anomalies related to the EAWM variability.

\section{b. Circulation anomalies associated with the North Atlantic SST anomalies}

When the SSTI is positive, positive SLP anomalies dominate most of the Eurasian continent and negative SLP anomalies are present over the midlatitude North Pacific (Fig. 7a). This increases the pressure contrast between the Eurasian land and the North Pacific. (a) SSTI \& SLP

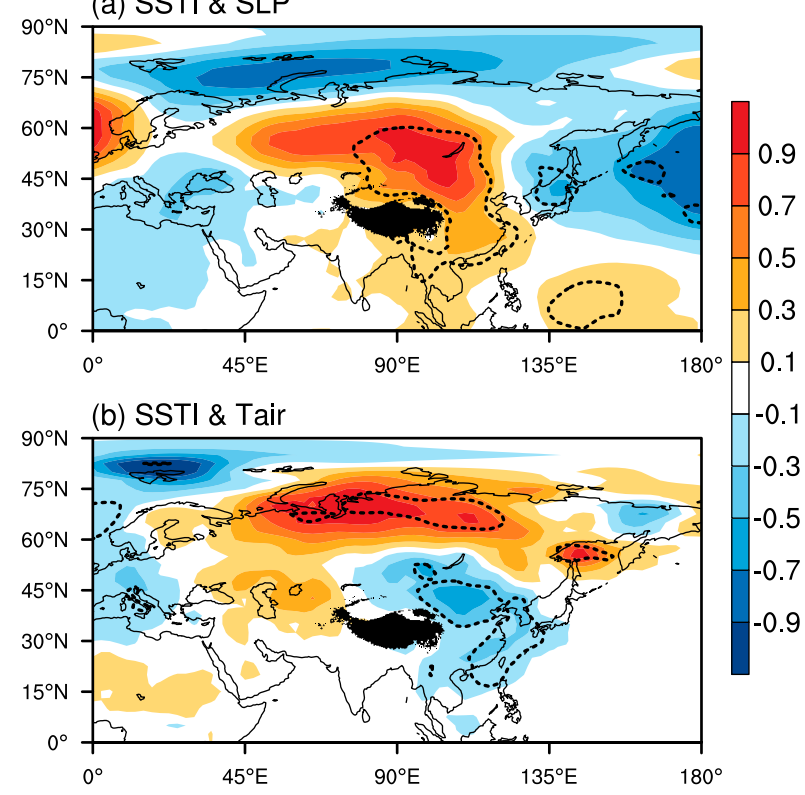

(c) SSTI \& UV850

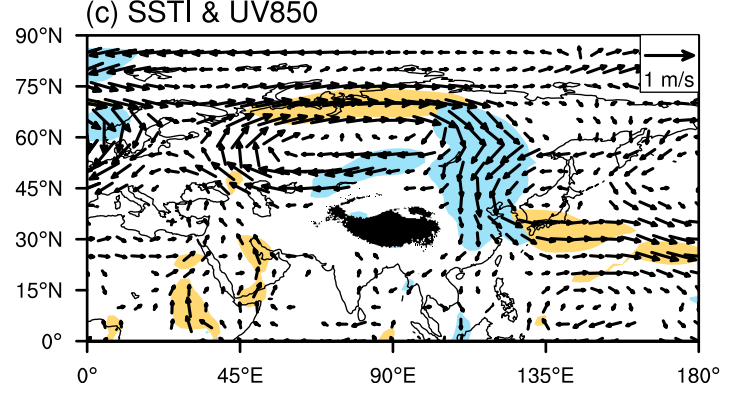

FIG. 7. Interannual anomalies of the following winter (a) SLP (hPa), (b) surface air temperature $\left({ }^{\circ} \mathrm{C}\right.$ ), and (c) 850 -hPa wind $\left(\mathrm{m} \mathrm{s}^{-1}\right)$ obtained by regression on the July-August(0) North Atlantic dipole SSTI for the period 1979-2016. The wind scale is shown on the top-right corner in (c). The shaded areas denote that the anomalies of SLP in (a), surface air temperature in (b), and either $u$ wind or $v$ wind in (c) are significant at the $95 \%$ confident level according to the Student's $t$ test.

Correspondingly, there is an anomalous anticyclone over the mid- and high-latitude Eurasia and an anomalous cyclone over the midlatitude North Pacific. Large anomalous northerlies are observed along the coast of East Asia (Fig. 7c). The anomalous northerly winds bring cooler air from higher latitudes, leading to significant cooling over the midlatitude Asia (Fig. 7b). Large warming is observed over the northern Eurasian continent, which is associated with anomalous anticyclone (Fig. 7c) that is accompanied by anomalous descent and reduced cloudiness, allowing more solar radiation to reach the land surface. These results indicate that the summer North Atlantic dipole SST anomaly pattern has a large impact on the following winter climate over the Eurasian land. In particular, the EAWM is enhanced 


\section{(a) SSTI \& H500}

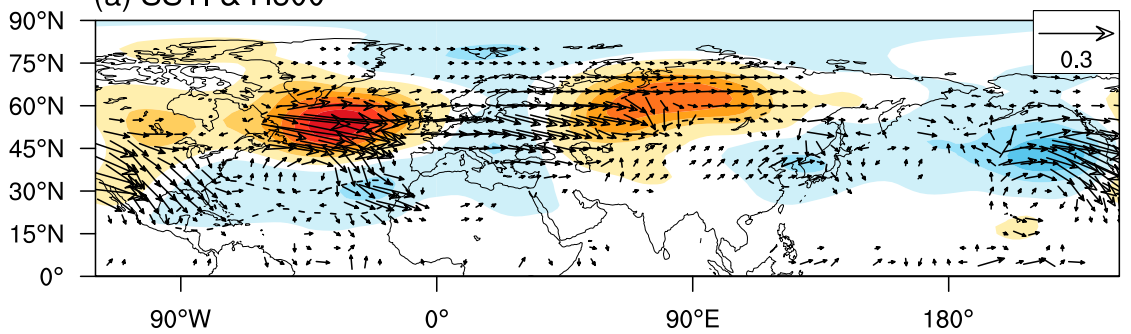

(b) SSTI \& H2OO

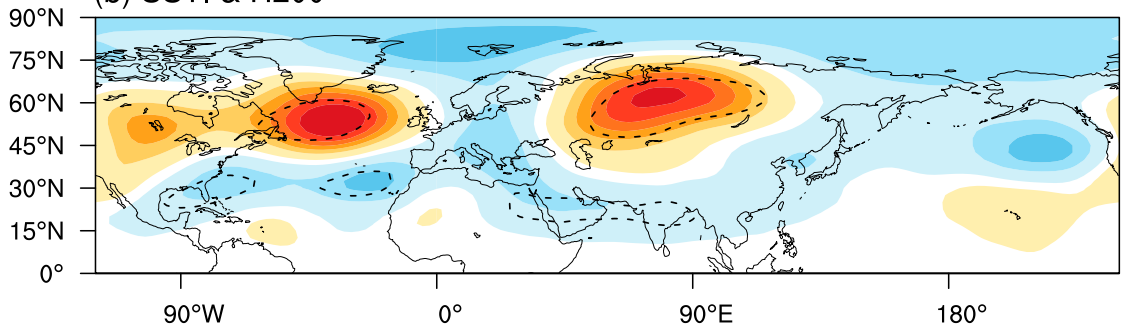

(c) Model \& $\mathrm{H} 500$

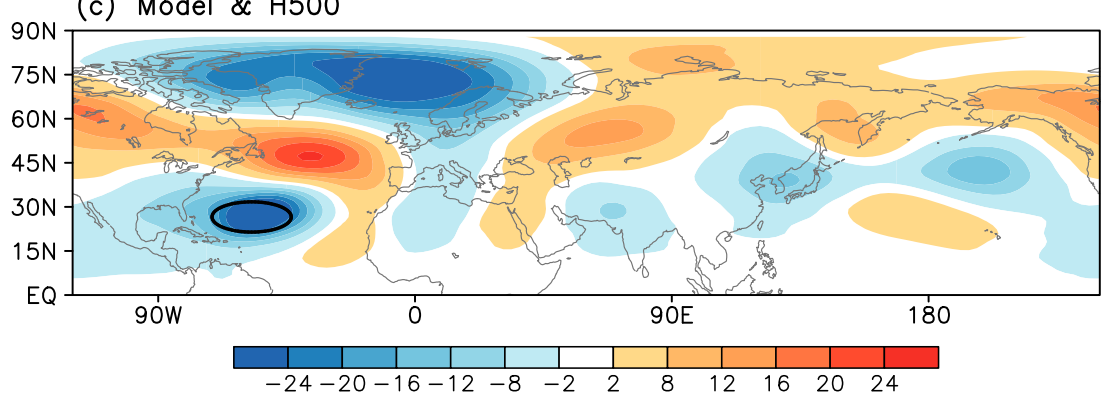

FIG. 8. Interannual anomalies of the following winter (a) 500-hPa geopotential height (m; shading) and 500-hPa wave activity flux ( $\mathrm{m}^{2} \mathrm{~s}^{-2}$; vectors) and (b) 200-hPa geopotential height (m; shading) obtained by regression on the July-August (0) North Atlantic dipole SSTI for the period 1979-2016. The wave activity flux scale is shown on the top-right corner in (a). The shaded areas denote that the geopotential height anomalies are significant at the $95 \%$ confident level according to the Student's $t$ test. (c) The 40-day mean 500-hPa geopotential height (m) in the LBM model in response to imposed anomalous cooling over the subtropical western North Atlantic.

as indicated by the increase in the west-east pressure contrast and anomalous northerly winds over East Asia (Figs. 7a,c).

At $500 \mathrm{hPa}$, a noticeable feature is a wave train-like structure, characterized by two positive height anomalies over the mid-high-latitude North Atlantic and northern Siberia and two negative ones over the western Europe and the midlatitude North Pacific (Fig. 8a). The above wave pattern indicates an enhanced ridge around the Ural Mountains and a deepened East Asian trough in the middle troposphere. Such a circulation anomaly pattern is favorable for enhanced Siberian high and anomalous northerly winds in the lower troposphere over East Asia, leading to stronger EAWM (Zhang et al. 1997). The geopotential height anomaly pattern features a typical positive phase of the EU pattern (e.g.,
Liu et al. 2014; Wang et al. 2019), which facilitates a strong EAWM (e.g., Liu et al. 2014; Wang and Chen 2014). This result agrees with $\mathrm{Li}$ (2004) who suggested that the SST anomalies in the North Atlantic may excite an EU-like wave train. The 200-hPa geopotential height anomalies show a distribution similar to that at $500 \mathrm{hPa}$ (Fig. 8a vs Fig. 8b), indicating a barotropic vertical structure of the atmospheric response in winter. The wave train is illustrated by 500 -hPa wave activity flux anomalies. The subtropical North Atlantic appears to be a source region of wave activity fluxes that extend northward and then eastward to Eurasia (Fig. 8a). This wave pattern appears to be emanated by anomalous divergence over the subtropical North Atlantic in winter. This is confirmed by anomalous descent motion at $500 \mathrm{hPa}$ over the subtropical North Atlantic (figure not 


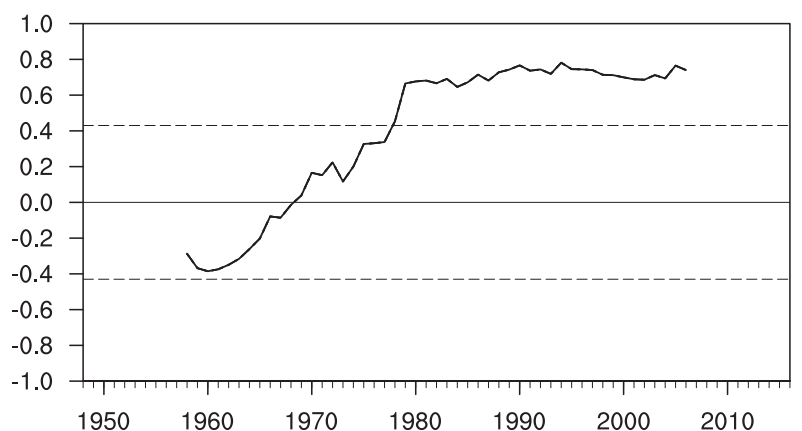

FIG. 9. The 21-yr sliding correlation between the Nindex of EAWM and the preceding July-August(0) North Atlantic dipole SSTI. The years are labeled based on the central year of the 21-yr window. The horizontal dashed lines indicate the $95 \%$ confidence level.

shown). The anomalous divergence may be associated with in situ negative SST anomalies (Figs. 4e,f) that induce higher surface pressure and lower-level divergence (Lindzen and Nigam 1987).

To confirm the excitation of the wave train, we conducted model experiments with a linear baroclinic model (LBM) with anomalous heating specified. The LBM is a primary equation model (Watanabe and Kimoto 2000; Watanabe and Jin 2003). The model has a horizontal resolution of T42 and 20 sigma levels in the vertical. Anomalous cooling is specified over the western subtropical Atlantic with a heating rate of $-1.5^{\circ} \mathrm{Cday}^{-1}$ at the center on the sigma level of 0.8 (Fig. $8 \mathrm{c}$ ). The model is integrated for 65 days, and we show the mean of 2160 days in Fig. 8c. The model response features a wave train over the North Atlantic and Eurasia (Fig. 8c). The distribution of height anomalies resembles the observations (Fig. 8a) though there are some differences in the magnitude and location of height anomalies.

Based on the above analyses, we propose the following processes connecting summer North Atlantic dipole SST anomaly pattern to winter Asian climate anomalies. The atmospheric wind anomalies in springsummer generate a dipole SST anomaly pattern in the North Atlantic in summer through surface heat flux changes. The dipole SST anomaly pattern changes to a tripole SST pattern in winter due to the air-sea interaction processes (Fig. 4). The SST anomalies in the North Atlantic (Figs. 4e,f) excite an atmospheric wave train in winter that propagates eastward to mid-highlatitude East Asia (Fig. 8), inducing an anomalous EAWM (Fig. 7). In brief, the link between preceding summer North Atlantic dipole SST anomalies and the EAWM is due to the evolution of the SST anomaly pattern in the North Atlantic and the influence of winter North Atlantic tripole SST anomalies on atmospheric circulation. Another feature to note is that significant atmospheric circulation anomalies in winter are limited to the mid-high latitudes and there are no obvious signals in the tropics (Figs. 7, 8). Chen et al. (2014a) pointed out that the northern component of EAWM is mainly affected by the midlatitude circulation systems, including the Siberian high and the East Asian trough, and the southern component of EAWM is mainly related to the tropical circulation systems. This confirms again that the summer North Atlantic dipole SST anomalies have a closer relation to the northern component than the southern component of the EAWM variability.

\section{Interdecadal changes in the relationship between the North Atlantic summer SST and EAWM variability}

Another important question is whether the relationship between summer North Atlantic SST and EAWM experiences significant interdecadal changes in the past. To address this question, the time period of analysis is extended from the period of 1979-2016 to 1948-2016 in this section. Sliding correlation coefficients between the July-August North Atlantic dipole SST index and Nindex are calculated with a 21-yr window (Fig. 9). The labeled years in Fig. 9 denotes the central year of the 21-yr window.

Apparently, the sliding correlation coefficient shows an obvious upward trend during 1950s through 1970s and remains at a high value since the late 1970s (Fig. 9). The correlation coefficient is positive and statistically significant at the $95 \%$ confidence level after 1978, while it is insignificant before 1978. Similar results are obtained when different lengths of window (e.g., 17, 19, and 23 years) are employed to calculate the sliding correlation coefficients (figures not shown). In the following analyses, we select two epochs, 1956-76 as the low correlation period and 1984-2004 as the high correlation period, to further investigate the unsteady relationship between the summer North Atlantic dipole SST anomaly pattern and the northern component of EAWM. The correlation coefficient between the JulyAugust North Atlantic dipole SSTI and Nindex is -0.08 and 0.78 , respectively, for the above two epochs.

During 1984-2004, the SSTI-related circulation anomalies feature a strengthened Siberian high (Fig. $10 \mathrm{~b}$ ), anomalous northerlies along the East Asian coast (Fig. 10f), and lower surface temperature over most of East Asia (Fig. 10d), reflecting a stronger-than-normal EAWM. These anomalies are consistent with those derived from the period 1979-2016 (Fig. 7). During 195676 , in contrast, significant signals are located in the high latitudes and the anomalies over East Asia are weak and insignificant. Significant positive SLP anomalies are 
(a) $1956-1976$ SLP

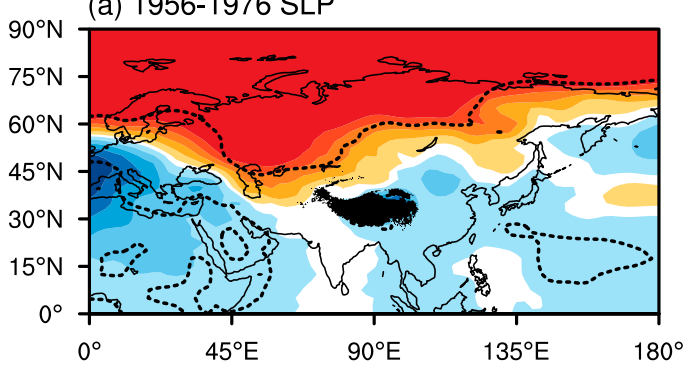

(c) 1956-1976 Tair

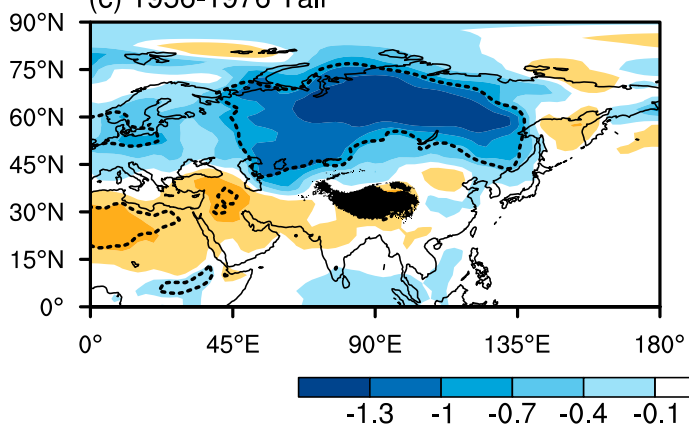

(b) 1984-2004 SLP

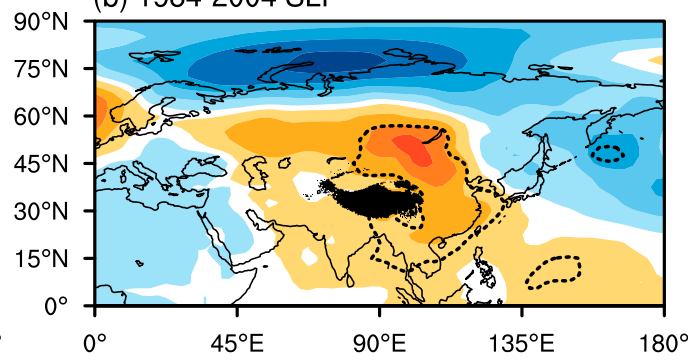

(d) 1984-2004 Tair

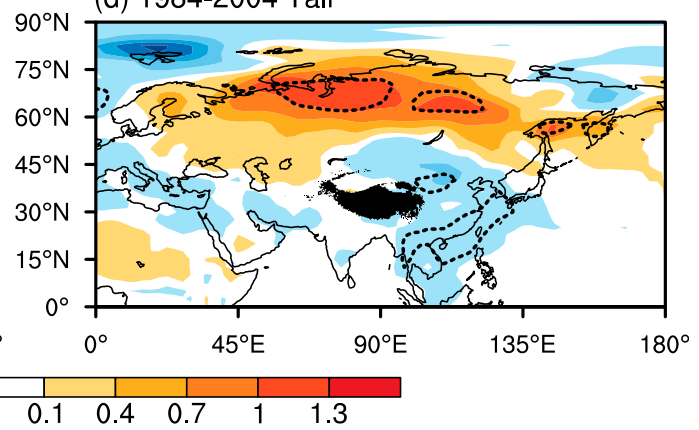

(e) 1956-1976 UV850

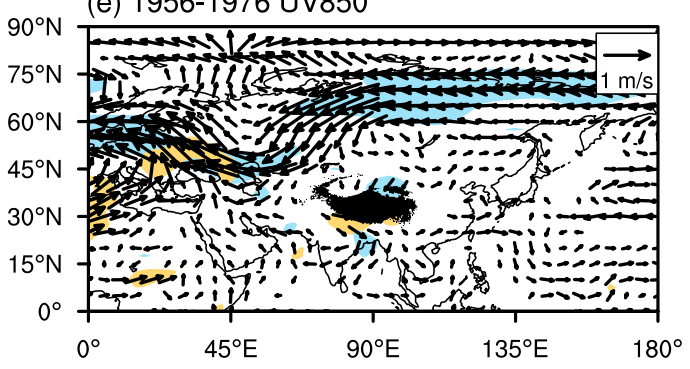

(f) 1984-2004 UV850

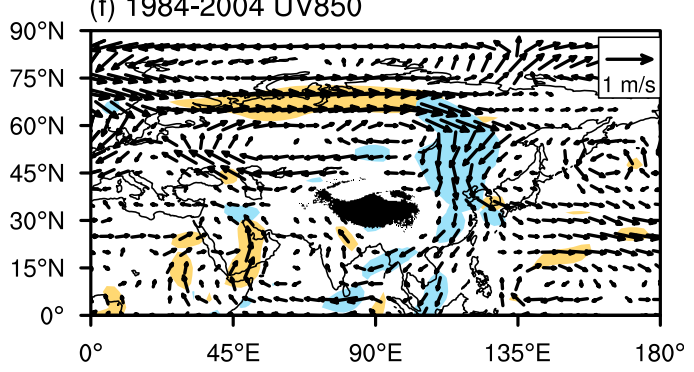

FIG. 10. As in Fig. 7, but for the period (left) 1956-76 and (right) 1984-2004.

seen north of $60^{\circ} \mathrm{N}$, and pronounced negative SLP anomalies are observed over Africa (Fig. 10a). Correspondingly, there are obvious easterly wind anomalies (Fig. 10e), accompanied by broad negative temperature anomalies (Fig. 10c) in the high latitudes of Eurasia. These results reveal that the connection of the summer North Atlantic dipole SST pattern with the EAWM variability is quite different between the two epochs.

During 1984-2004, a wave pattern extends from the North Atlantic through Eurasia to East Asia and a source region of wave activity fluxes is located over the subtropical North Atlantic (Fig. 11b). Two positive height anomalies appear over the North Atlantic and northern Asia and two negative ones are observed over the western Europe and the midlatitude North Pacific. This indicates a large change in both the East Asian trough (Fig. 11b) and the East Asian westerly jet (not shown). The results are similar to those obtained in 1979-2016 (section 4 and Fig. 8). During 1956-76, the geopotential height anomalies feature an obvious north- south contrast with positive anomalies over the polar region and negative anomalies over the midlatitudes extending from the North Atlantic to Russia (Fig. 11a). A wave train is observed from the western North Atlantic, going first northeastward to Greenland, then being divided into two branches, one turning southeastward to the eastern North Atlantic and the other one turning northeastward to the Arctic Ocean. In comparison, wave activity flux anomalies are located at higher latitudes and are relatively weaker over the midlatitude East Asia during 1956-76 than during 1984-2004. As a consequence, there are no obvious anomalies in the intensity of both the East Asian trough (Fig. 11a) and the East Asian westerly jet (not shown) during 195676. Note that the atmospheric response is barotropic over the mid- and high latitudes during both of the two epochs (not shown).

The above results reconfirm that anomalous atmospheric wave trains from the North Atlantic to East Asia play an important role in the formation of atmospheric 
(a) $1956-1976$

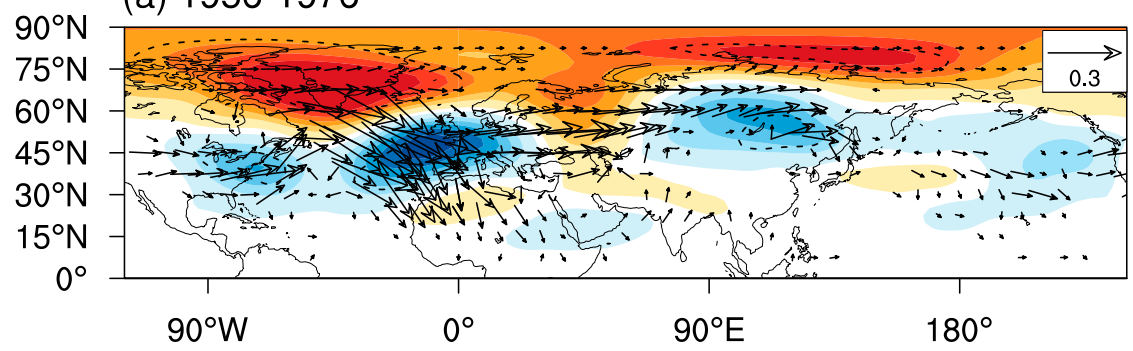

(b) $1984-2004$

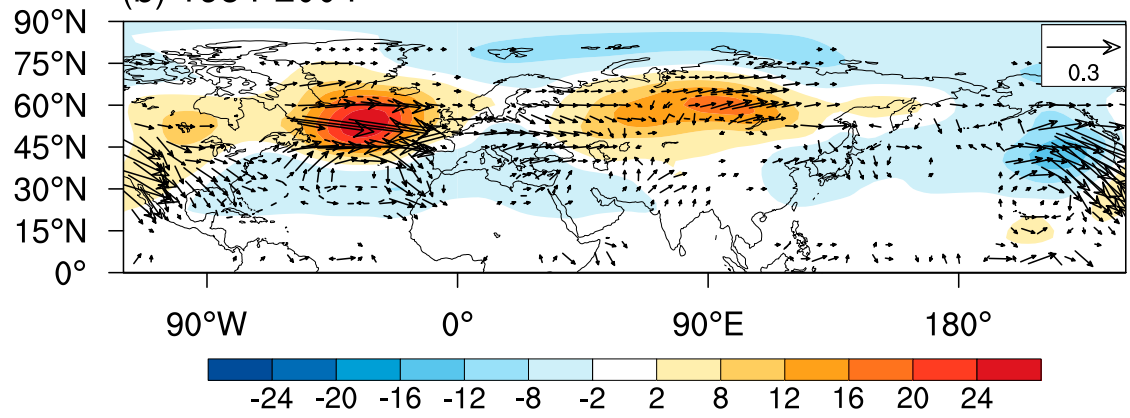

FIG. 11. Interannual anomalies of the following winter geopotential height ( $\mathrm{m}$; shading) and wave activity flux $\left(\mathrm{m}^{2} \mathrm{~s}^{-2}\right.$; vectors) at $500-\mathrm{hPa}$ obtained by regression on the JulyAugust(0) North Atlantic dipole SSTI for the period (a) 1956-76 and (b) 1984-2004. The wave activity flux scale is shown on the top-right corner. The shaded areas denote that the geopotential height anomalies are significant at the 95\% confident level according to the Student's $t$ test.

circulation anomalies over East Asia related to the preceding summer North Atlantic dipole SST anomaly pattern during 1984-2004, which further lead to an anomalous EAWM. By contrast, during 1956-76, the lack of atmospheric wave trains explains the weak atmospheric circulation anomalies over East Asia. Thus, the connection between the summer North Atlantic dipole SST anomaly pattern and the northern component of EAWM is weak during this period.

In view of the importance of the North Atlantic SST anomalies in the formation of the atmospheric wave train, we compare the evolution of the North Atlantic dipole SSTI-related SST anomalies during the two epochs. During 1984-2004, a dipole SST anomaly pattern develops in March-April with negative and positive SST anomalies, respectively, in the midlatitudes and subtropics of the North Atlantic (Fig. 12b). The dipole pattern intensifies in May-June (Fig. 12d), attains the maximum in July-August (Fig. 12f), and weakens in September-October (Fig. 12h). In November-December, the dipole SST anomaly pattern turns into a tripole SST anomaly pattern with significant positive anomalies in the midlatitudes and tropics and significant negative anomalies in the subtropics (Fig. 12j). The tripole SST anomaly pattern is maintained to January-February though with reduced magnitude (Fig. 121). The evolution of SST anomalies during 1984-2004 bears a close resemblance to that in 1979-2016 except that the tripole SST pattern in winter is more obvious in 1984-2004 than in 1979-2016 (Figs. 4e,f vs Figs. 12j,1). The wave pattern shown in Fig. 11b appears to be induced by the North Atlantic tripole SST anomalies in winter. During 195676 , positive and negative SST anomalies are located north and south of $30^{\circ} \mathrm{N}$ in the western North Atlantic, respectively, in March-April (Fig. 12a). The dipole SST anomaly pattern is weak in May-June (Fig. 12c), becomes obvious in July-August (Fig. 12e), and is weakened in September-October (Fig. 12g). In NovemberDecember, negative SST anomalies shift southwestward to the western North Atlantic and positive SST anomalies along the coast of Africa are weakened (Fig. 12i). In January-February, negative SST anomalies have shrunk to a narrow region around $30^{\circ} \mathrm{N}$ in the western North Atlantic and the positive SST anomalies are still seen in the subtropical eastern North Atlantic (Fig. 12k). The wave pattern seen in Fig. 11a appears to be emanated by anomalous negative SST anomalies in the western North Atlantic. By contrast, the evolution of SST anomalies from summer to winter displays notable differences between the periods of 1956-76 and 

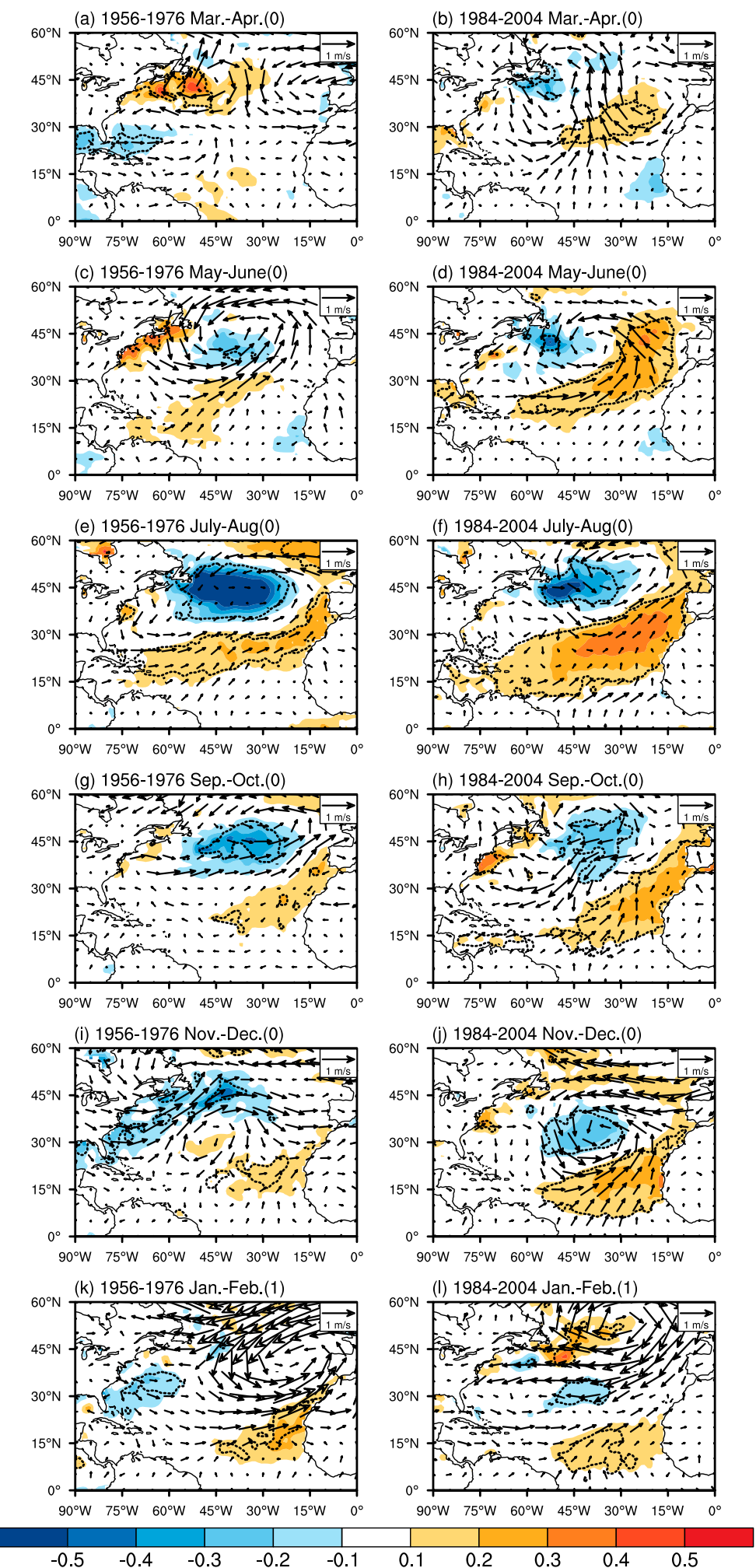

FIG. 12. As in Fig. 4, but for the period (left) 1956-76 and (right) 1984-2004. 
1984-2004. During 1956-76, the SST anomalies in the midlatitudes are weak and no tripole SST anomaly pattern is established in winter (Figs. 12i,k).

To confirm the role of the tripole SST anomaly pattern in winter in linking the summer dipole SST anomaly pattern and the northern component of the EAWM, we compare the relationship between a tripole SST index and the Nindex between the periods of 1956-76 and 1984-2004. The tripole SST index is defined using areamean January-February SST anomalies averaged over three regions: $43^{\circ}-53^{\circ} \mathrm{N}$ and $49^{\circ}-31^{\circ} \mathrm{W}(\mathrm{N}), 28^{\circ}-34^{\circ} \mathrm{N}$ and $50^{\circ}-30^{\circ} \mathrm{W}(\mathrm{M})$, and $7^{\circ}-17^{\circ} \mathrm{N}$ and $47^{\circ}-31^{\circ} \mathrm{W}(\mathrm{S})$ as follows: $\mathrm{N}+\mathrm{S}-\mathrm{M}$. The above three regions are selected based on the distribution of correlation in Fig. 4f. The correlation coefficient between the tripole SST index and the Nindex is -0.34 and 0.37 , respectively, during 1956-76 and 1984-2004. The correlation coefficient between the tripole SST index and the dipole SST index is 0.18 and 0.58 , respectively, during 1956-76 and 1984-2004. If we only consider the part of the tripole SST index related to the July-August dipole SST index, the correlation coefficient between the tripole SST index and the Nindex is -0.04 and 0.72 , respectively, during 1956-76 and 1984-2004.

Pronounced cyclonic wind anomalies are seen over the midlatitude North Atlantic in summer during both two epochs (Figs. 12c-f). It is obvious that the wind anomalies display a very different pattern between two epochs in fall and winter. The center of the anomalous cyclone in September-October is located at higher latitudes during 1956-76 than during 1984-2004 (Figs. $12 \mathrm{~g}, \mathrm{~h})$. No large wind anomalies are seen over the subtropics in September-October during 1956-76 (Fig. 12g). During 1984-2004, an anomalous cyclone covers the North Atlantic in November-December (Fig. 12j) and an anomalous anticyclone appears over the high latitude North Atlantic in January-February (Fig. 121). By contrast, during 1956-76, there is an anomalous anticyclone over the subtropics in November-December (Fig. 12i) and an anomalous cyclone over the eastern North Atlantic in January-February (Fig. 12k).

The spatial distribution of surface NHF anomalies over the North Atlantic is similar to that of SST anomalies during both two epochs (Figs. 12, 13). Positive (negative) NHF anomalies correspond to SST warming (cooling). This indicates that the formation and evolution of SST anomalies are closely related to changes in surface heat fluxes. The evolutions of surface wind and NHF anomalies during 1984-2004 bear a close resemblance to those derived from 1979 to 2016 (Fig. 4 vs Figs. 12b,d,f,h,j,l and Figs. 6b,e,h,k,n,q vs Figs. $13 b, d, f, h, j, l)$. Since the relationship between surface wind and NHF during 1979-2016 is documented in section 4a, it is not repeated in this section. During 195676 , positive SST anomalies in the western midlatitudes in March-April are likely associated with anomalous anticyclone and anomalous easterly winds (Fig. 12a) that reduces cloud and surface wind speed, respectively. Together they lead to positive NHF anomalies (Fig. 13a). In May-June and July-August, northerly (southerly) wind anomalies in the west (east) flank of the anomalous cyclone increase (reduce) sea-air humidity difference, which favors cold (warm) SST anomalies through enhancing (suppressing) upward LHF and thus reducing (increasing) NHF input into the ocean (Figs. $13 \mathrm{c}, \mathrm{e})$. The anomalous westerlies over the subtropical North Atlantic (Figs. 12c,e) weaken northeasterly trade winds and reduce upward LHF and thus induce positive NHF anomalies (Figs. 13c,e). In September-October, SST and NHF anomalies display a similar spatial pattern but with opposite signs (Fig. 12g vs Fig. 13g), leading to a weakened dipole SST anomaly pattern. In NovemberDecember, negative NHF anomalies along the west coast (Fig. 13i) may be explained by anomalous westerlies on the northwest side of the anomalous anticyclone (Fig. 12i) that increase local wind speed and upward LHF, contributing to the formation of negative SST anomalies in the western North Atlantic (Fig. 12i). The northerly wind anomalies over eastern North America bring drier air from the land, enhancing the sea-air humidity difference, which may also contribute to negative NHF anomalies in the western North Atlantic. In January-February, positive NHF anomalies in the high latitudes (Fig. 13k) are related to the easterly wind anomalies over the northern part of the anomalous cyclone (Fig. 12k) that reduce local wind speed and upward LHF. Accordingly, the region of negative SST anomalies in the western North Atlantic has shrunk (Fig. 12k).

The correspondence of SST and the wind anomaly pattern over the North Atlantic indicates a coupled variation during 1984-2004 and 1979-2016. As pointed out in section $4 \mathrm{a}$, the anomalous atmospheric circulation over the North Atlantic in spring and summer results in the formation of a summer dipole SST anomaly pattern through changes in surface heat fluxes (Figs. 4a-c vs Figs. 6b,e,h and Figs. 12b,d,f vs Figs. 13b,d,f). The SST anomaly pattern appears to contribute to changes in the strength and location of the atmospheric circulation from summer to winter (Fig. 4 and Figs. $12 \mathrm{~b}, \mathrm{~d}, \mathrm{f}, \mathrm{h}, \mathrm{j}, \mathrm{l})$. The atmospheric circulation anomaly, in turn, leads to the switch from the dipole SST pattern in summer to a tripole SST anomaly pattern in the following winter (Figs. 4e,f and Figs. 12j,l). Thus, air-sea interaction plays a major role in the evolution of the North Atlantic SST anomalies from summer to winter 

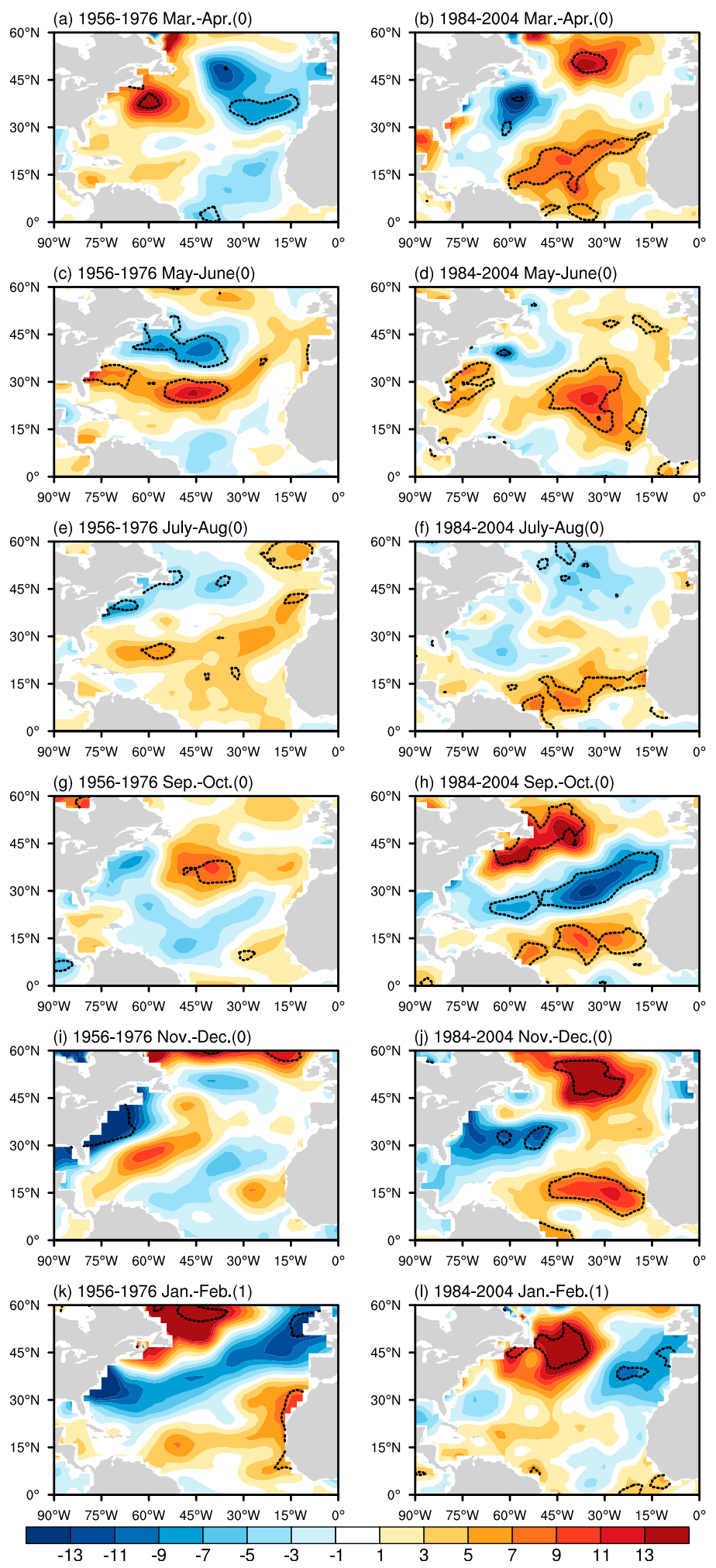

FIG. 13. As in the center column of Fig. 6, but for NHF anomalies during the period (left) 1956-76 and (right) 1984-2004. 
during 1984-2004 and 1979-2016. In contrast, during 1956-76, the evolution of atmospheric circulation cannot be well explained by SST anomalies, such as the northward movement of the cyclone from July-August to September-October (Figs. 12e,g), and the occurrence of the anomalous cyclone in January-February (Fig. 12k). Thus, the atmospheric circulation over the North Atlantic may be affected by factors other than local SST anomalies and the air-sea coupling is weak during this period. As a result, the North Atlantic tripole SST anomaly pattern is not established in winter during 1956-76.

\section{Summary and discussions}

The present study investigated the impacts of the North Atlantic SST anomalies on the two components of the EAWM variability. It is found that the northern component of the EAWM variability is associated with the preceding summer North Atlantic SST anomalies characterized by a dipole pattern with significant negative and positive anomalies in the midlatitude and subtropical North Atlantic, respectively. However, the southern component of the EAWM variability shows a weak relationship to the preceding summer North Atlantic SST anomalies except in small regions. Based on the distribution of the correlation of July-August North Atlantic SST with an index for the northern component of EAWM (Nindex), a North Atlantic dipole SST index has been defined to measure the summer North Atlantic SST anomaly pattern. A positive dipole SSTI denotes positive SST anomalies in the subtropics and negative SST anomalies in the midlatitudes.

During 1979-2016, anomalous atmospheric winds over the North Atlantic in spring and summer result in the formation of a summer dipole SST anomaly pattern through changes in surface heat fluxes. In turn, the induced SST anomalies provide a feedback on the atmosphere, modifying the location and intensity of anomalous circulation over the North Atlantic. Meanwhile, the atmospheric circulation anomaly, in turn, leads to change of the North Atlantic SST anomalies from a dipole pattern in summer to a tripole pattern in the following winter, which features same-sign SST anomalies in the tropical and midlatitude North Atlantic Ocean and opposite-sign SST anomalies in the subtropical North Atlantic Ocean. Thus, air-sea interactions are involved in the evolution of the North Atlantic SST and wind anomalies. Finally, the North Atlantic tripole SST anomalies in winter excite an atmospheric wave train extending from the North Atlantic through Eurasia to East Asia. These enhance (weaken) the Siberian high, the East Asian trough, and the East Asian

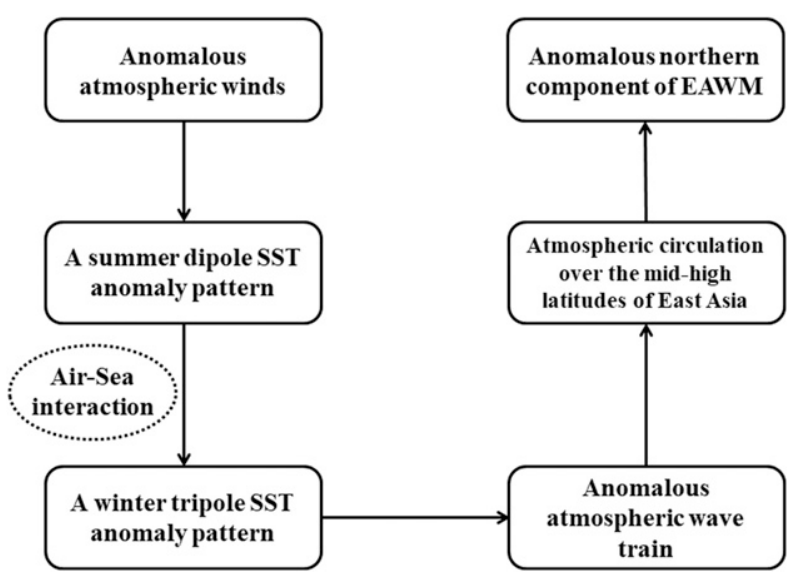

FIG. 14. A schematic map of the physical processes connecting the summer North Atlantic dipole SST anomaly pattern to the northern component of the EAWM.

westerly jet, resulting in a strong (weak) northern component of EAWM. As such, the northern component of the EAWM variability is tied to the preceding summer North Atlantic dipole SST anomaly pattern. The physical processes connecting preceding summer North Atlantic dipole SST anomaly pattern to the northern component of the EAWM are presented in Fig. 14.

The relationship of the northern component of EAWM to the summer North Atlantic dipole SST anomaly pattern experienced an obvious change in the late 1970s. The relationship is strong and statistically significant after the late 1970s, whereas the connection is weak and insignificant before the late 1970s. During 1984-2004 (high correlation epoch), the North Atlantic dipole SST anomaly pattern in summer changes to a tripole SST anomaly pattern in the following winter. During 1956-76 (low correlation epoch), no significant tripole SST anomaly pattern is established in winter. The anomalous wave activity fluxes are located at higher latitudes and are relatively weaker over East Asia during 1956-76 than during 1984-2004. The lack of atmospheric wave trains explains the weak atmospheric circulation anomalies over East Asia, leading to a weak connection between the northern component of EAWM and the preceding summer North Atlantic dipole SST anomaly pattern during $1956-76$.

The interdecadal change in the relationship between preceding summer dipole SST anomaly pattern and the northern component of EAWM is related to whether a tripole SST anomaly pattern forms in winter. This appears to be associated with the wind anomaly distribution. During 1984-2004, the wind anomalies over the North Atlantic feature a NAO distribution (Figs. 12h, j, l) and thus tend to be aligned with climatological mean winds. Under such cases, the wind speed anomalies are 
large, inducing large LHF anomalies with a tripole pattern (Figs. 13h,j), favorable for the formation of a tripole SST anomaly in winter. During 1956-76, the wind anomaly distribution over the North Atlantic differs from the NAO pattern (Figs. 12i,j). The wind speed anomalies are not so large and the induced LHF anomalies are different from the tripole pattern (Figs. 13g,i). As such, the tripole SST anomaly pattern does not form in winter. The above difference in wind speed effect between the two periods appears to be related to the decadal mean wind change. The mean surface wind difference of 1984-2004 minus 1956-76 in November-December displays a distribution similar to the NAO pattern (not shown). In fact, the winter NAO index experienced a change from lower values to higher values around the late 1970s. Further studies are needed to identify whether other factors play a role in the interdecadal change in the preceding summer North Atlantic SST and the EAWM relationship.

Previous studies have indicated that the NAO influences the winter climate in Eurasia. Does the NAO play a role in the connection between the preceding summer North Atlantic SST anomalies and the EAWM variability. We calculated the correlation coefficient of the winter Nindex and the July-August dipole SSTI with the winter NAO index during 1956-76 and 19792016 on the interannual time scale. It turns out that the winter NAO index has a weak relationship with the Nindex and SSTI during both periods. This is consistent with Chen et al. (2014a) that showed that NAO has no significant impact on the EAWM variability on the interannual time scale, but it is closely related to the midhigh-latitude EAWM variability on the interdecadal time scale. The correlation coefficients of the winter NAO and the Nindex on the interdecadal time scale are close during the two periods, -0.65 and -0.68 , respectively, during 1956-76 and 1984-2004. Thus, the influence of summer North Atlantic SST anomalies on the following winter northern component of EAWM may be independent of NAO on the interannual time scale.

The formation of summer dipole SST anomaly pattern is attributed to anomalous winds over the midlatitude North Atlantic in spring and summer. One issue is what generates anomalous winds over the North Atlantic. According to Cassou et al. (2004), anomalous tropical heating associated with the displacement of the Atlantic intertropical convergence zone may produce a cyclonic circulation off Newfoundland. The different evolution of the North Atlantic SST anomalies from summer to winter appears to be related to the different strength of the airsea interaction before and after late 1970s. An issue is what may have caused the difference in the strength of air-sea interaction over the North Atlantic. Since the atmospheric response to SST anomalies may be dependent upon the mean state, the mean SST change may play a role in the interdecadal changes in the relationship between the North Atlantic SST and EAWM. Further studies are needed to address the above issues.

Acknowledgments. The comments of three anonymous reviewers are appreciated. This study is supported by the National Natural Science Foundation of China grants (41705051, 41530425, 41775080, and 41721004) and Scientific Research Fund of Chengdu University of Information Technology (KYTZ201726). The HadISST data were extracted from http://www.metoffice.gov. uk/hadobs/hadisst/. The NCEP-NCAR reanalysis data were obtained by ftp://ftp.cdc.noaa.gov/Datasets/.

\section{REFERENCES}

Cassou, C., C. Deser, L. Terray, J. W. Hurrell, and M. D. Villon, 2004: Summer sea surface temperature conditions in the North Atlantic and their impact upon the atmospheric circulation in early winter. J. Climate, 17, 3349-3363, https://doi.org/10.1175/ 1520-0442(2004)017<3349:SSSTCI >2.0.CO;2.

Chen, S. F., and R. G. Wu, 2017: Interdecadal changes in the relationship between interannual variations of spring north Atlantic SST and Eurasian surface air temperature. J. Climate, 30, 3771-3787, https://doi.org/10.1175/JCLI-D-16-0477.1.

,-- , and W. Chen, 2015: The changing relationship between interannual variations of the North Atlantic Oscillation and northern tropical Atlantic SST. J. Climate, 28, 485-504, https:// doi.org/10.1175/JCLI-D-14-00422.1.

$\longrightarrow$, - $\longrightarrow$ and Y. Liu, 2016: Dominant modes of interannual variability in Eurasian surface air temperature during boreal spring. J. Climate, 29, 1109-1125, https://doi.org/10.1175/JCLID-15-0524.1.

Chen, W., H. F. Graf, and R. H. Huang, 2000: The interannual variability of East Asian winter monsoon and its relation to the summer monsoon. Adv. Atmos. Sci., 17, 48-60, https:// doi.org/10.1007/s00376-000-0042-5.

Chen, Z., R. G. Wu, and W. Chen, 2014a: Distinguishing interannual variations of the northern and southern modes of the East Asian winter monsoon. J. Climate, 27, 835-851, https://doi.org/10.1175/JCLI-D-13-00314.1.

,-- , and $-2014 \mathrm{~b}$ : Impacts of autumn Arctic sea ice concentration changes on the East Asian winter monsoon variability. J. Climate, 27, 5433-5450, https://doi.org/10.1175/ JCLI-D-13-00731.1.

Dee, D. P., and Coauthors, 2011: The ERA-Interim reanalysis: Configuration and performance of the data assimilation system. Quart. J. Roy. Meteor. Soc., 137, 553-597, https://doi.org/ 10.1002/qj.828.

Duchon, C. E., 1979: Lanczos filtering in one and two dimensions. J. Appl. Meteor., 18, 1016-1022, https://doi.org/10.1175/15200450(1979)018<1016:LFIOAT > 2.0.CO;2.

Hu, Z. Z., and B. H. Huang, 2006: Air-sea coupling in the North Atlantic during summer. Climate Dyn., 26, 441-457, https:// doi.org/10.1007/s00382-005-0094-4.

Kalnay, E., and Coauthors, 1996: The NCEP/NCAR 40-Year Reanalysis Project. Bull. Amer. Meteor. Soc., 77, 437-471, https:// doi.org/10.1175/1520-0477(1996)077<0437:TNYRP>2.0.CO;2. 
Kang, L.-H., W. Chen, L. Wang, and L.-J. Chen, 2009: Interannual variations of winter temperature in China and their relationship with the atmospheric circulation and sea surface temperature (in Chinese). Climatic Environ. Res., 14, 45-53.

Klein, S. A., B. J. Soden, and N.-C. Lau, 1999: Remote sea surface temperature variations during ENSO: Evidence for a tropical atmospheric bridge. J. Climate, 12, 917-932, https://doi.org/ 10.1175/1520-0442(1999)012<0917:RSSTVD>2.0.CO;2.

Kobayashi, S., and Coauthors, 2015: The JRA-55 Reanalysis: General specifications and basic characteristics. J. Meteor. Soc. Japan, 93, 5-48, https://doi.org/10.2151/jmsj.2015-001.

Li, S. L., 2004: Impact of northwest Atlantic SST anomalies on the circulation over the Ural Mountains during early winter. J. Meteor. Soc. Japan, 82, 971-988, https://doi.org/10.2151/ jmsj.2004.971.

Lindzen, R., and S. Nigam, 1987: On the role of sea surface temperature gradients in forcing low-level winds and convergence in the tropics. J. Atmos. Sci., 44, 2418-2436, https://doi.org/ 10.1175/1520-0469(1987)044<2418:OTROSS > 2.0.CO;2.

Liu, G., L. R. Ji, S. Q. Sun, and Y. F. Xin, 2012: Low- and mid-high latitude components of the East Asian winter monsoon and their reflecting variations in winter climate over eastern China. Atmos. Ocean. Sci. Lett., 5, 195-200, https://doi.org/10.1080/ 16742834.2012.11446985.

,,,--- and -2013 : A discussion on the East Asian winter monsoon index-Differences between the East Asian winter monsoon at the mid-high latitudes and that at the low latitudes (in Chinese). Chin. J. Atmos. Sci., 37, 755-764.

Liu, Y. Y., L. Wang, W. Zhou, and W. Chen, 2014: Three Eurasian teleconnection patterns: Spatial structures, temporal variability, and associated winter climate anomalies. Climate Dyn., 42, 2817-2839, https://doi.org/10.1007/s00382-014-2163-z.

Rayner, N. A., D. E. Parker, E. B. Horton, C. K. Folland, L. V. Alexander, D. P. Rowell, E. C. Kent, and A. Kaplan, 2003: Global analyses of sea surface temperature, sea ice, and night marine air temperature since the late nineteenth century. J. Geophys. Res., 108, 4407, https://doi.org/10.1029/ 2002JD002670.

Smith, T. M., R. W. Reynolds, T. C. Peterson, and J. Lawrimore, 2008: Improvements to NOAA's historical merged landocean surface temperature analysis (1880-2006). J. Climate, 21, 2283-2296, https://doi.org/10.1175/2007JCLI2100.1.

Tanimoto, Y., H. Nakamura, T. Kagimoto, and S. Yamane, 2003: An active role of extratropical sea surface temperature anomalies in determining anomalous turbulent heat flux. J. Geophys. Res., 108, 3304, https://doi.org/10.1029/2002JC001750.
Wang, B., Z. W. Wu, C. P. Chang, J. Liu, J. P. Li, and T. J. Zhou, 2010: Another look at interannual-to-interdecadal variations of the East Asian winter monsoon: The northern and southern temperature modes. J. Climate, 23, 1495-1512, https://doi.org/ 10.1175/2009JCLI3243.1.

Wang, L., and W. Chen, 2014: An intensity index for the East Asian winter monsoon. J. Climate, 27, 2361-2374, https://doi.org/ 10.1175/JCLI-D-13-00086.1.

_- Y. Y. Liu, Y. Zhang, W. Chen, and S. F. Chen, 2019: Timevarying structure of the wintertime Eurasian pattern: Role of the North Atlantic sea surface temperature and atmospheric mean flow. Climate Dyn., 52, 2467-2479, https://doi.org/ 10.1007/s00382-018-4261-9.

Watanabe, M., and M. Kimoto, 2000: Atmosphere-ocean thermal coupling in the North Atlantic: A positive feedback. Quart. J. Roy. Meteor. Soc., 126, 3343-3369, https://doi.org/10.1002/ qj. 49712657017.

_ , and F. F. Jin, 2003: A moist linear baroclinic model: Coupled dynamical-convective response to El Niño. J. Climate, 16, 1121-1139, https://doi.org/10.1175/1520-0442(2003)16<1121: AMLBMC $>2.0 . \mathrm{CO} ; 2$.

Wu, B. Y., R. H. Zhang, and R. Arrigo, 2006: Distinct modes of the East Asian winter monsoon. Mon. Wea. Rev., 134, 2165-2179, https://doi.org/10.1175/MWR3150.1.

Wu, J.-J., and Z.-W. Wu, 2019: Inter-decadal change of the spring NAO impact on the summer Pamir-Tienshan snow cover. Int. J. Climatol., 39, 629-642, https://doi.org/10.1002/joc.5831.

Wu, R. G., S. Yang, S. Liu, L. Sun, Y. Lian, and Z. T. Gao, 2010: Changes in the relationship between northeast China summer temperature and ENSO. J. Geophys. Res., 115, D21107, https://doi.org/10.1029/2010JD014422.

summer temperature and North Atlantic SST. J. Geophys. Res., 116, D16116, https://doi.org/10.1029/2011JD015779.

Wu, Z.-W., and P. Zhang, 2015: Interdecadal variability of the mega-ENSO-NAO synchronization in winter. Climate Dyn., 45, 1117-1128, https://doi.org/10.1007/s00382-014-2361-8.

_- B. Wang, J.-P. Li, and F.-F. Jin, 2009: An empirical seasonal prediction model of the East Asian summer monsoon using ENSO and NAO. J. Geophys. Res., 114, D18120, https:// doi.org/10.1029/2009JD011733.

Zhang, Y., K. R. Sperber, and J. S. Boyle, 1997: Climatology and interannual variation of the East Asia winter monsoon: Results from the 1979-95 NCEP/NCAR reanalysis. Mon. Wea. Rev., 125, 2605-2619, https://doi.org/10.1175/1520-0493(1997) $125<2605$ :CAIVOT $>2.0 . \mathrm{CO} ; 2$. 